\title{
Circular supply chains and renewable chemical feedstocks: A network
}

\section{configuration analysis framework}

\author{
Jagjit Singh Srai ${ }^{\mathrm{a}, 1}$, Naoum Tsolakis ${ }^{\mathrm{a}}$, Mukesh Kumar ${ }^{\mathrm{a}}$, Wouter Bam ${ }^{\mathrm{b}}$ \\ a Centre for International Manufacturing, Institute for Manufacturing (IfM), Department of Engineering, \\ University of Cambridge, 17 Charles Babbage Road, Cambridge CB3 OFS, United Kingdom \\ ${ }^{b}$ Department of Industrial Engineering, Stellenbosch University, Stellenbosch, South Africa
}

\begin{abstract}
The aim of this research is to provide a comprehensive decision-making process and a framework for exploring the commercial viability of supply chains (SCs) arising from renewable chemical feedstocks (RCFs), towards delivering value-added intermediates or endproducts. To that end, we first introduce an inclusive hierarchical decision-making process that applies to all stakeholders involved in the design and management of circular SCs defined by RCF platform technologies. Thereafter, the identified decisions are encapsulated in a framework highlighting that the potential SC configuration alternatives are grounded on four essential theme areas, namely: (i) RCF, (ii) technology, (iii) market and (iv) value and viability. Our analysis highlights the significance of RCFs due to their emerging potential of replacing petrochemicals; however, existing research is evidently limited due to scope and data-related challenges, and the inherent complexity at the market side of the respective supply networks.
\end{abstract}

Keywords: Circular supply chains; Decision-making process; Network configuration analysis framework; Renewable chemical feedstocks; Viable supply chains.

\footnotetext{
${ }^{1}$ Corresponding author. Tel: +44 (0) 1223765 601; Fax: +44 (0) 1223464217.

E-mail address: jss46@,cam.ac.uk (Dr. Jagjit Singh Srai).
} 


\section{Introduction}

The circular economy era calls for supply chains (SCs) that enable the establishment of competitive, self-sustained and viable industrial systems (Lieder and Rashid 2016). More specifically, in the chemical industry compounds from renewable feedstocks are gaining an emerging role as substitutes for petroleum-based raw materials (Behr and Johnen 2009) in a range of industrially manufactured products like pharmaceuticals and electronics (Kawaguchi et al. 2016). However, renewable feedstocks-related challenges impede the adoption of sustainable value networks (Anuar and Abdullah 2016). Indeed, the adoption of renewable alternatives is highly complex stemming from the uncertainties in the substrate and technology options selection for delivering attractive intermediates and end-products to the market. The individual assessment and final integration of these evolution elements can then ensure overall commercial viability. In the SC field, the theoretical challenge is significant; the demanddriven network operations should be replaced by a renewable feedstock-driven evaluation that instigates technical and commercial development. In this context, the paper aims to develop a framework that enables the systematic exploration of renewable feedstock SCs where the development process involves evaluation of substrates, intermediates and final products, reversing the traditional demand-driven SC analysis.

Over the last four decades, the global chemical industry has recorded a remarkable growth in terms of output, from US\$ 171 billion in the 1970s to US\$ 4.12 trillion in 2012 (UNEP 2013). However, this industry is primarily reliant on crude oil-based feedstocks (Keim 2010) with the petrochemical sector accounting for over $30 \%$ of global industrial energy consumption (Brown et al. 2012) and generating around $18 \%$ of the direct industrial $\mathrm{CO} 2$ emissions, excluding electricity production (Benchaita 2013). In this regard, the chemical industry is actively pursuing strategies to integrate the use of renewable chemical feedstocks (RCFs) into existing and prospective SCs to enable their transition towards a circular economy paradigm 
(CEFIC 2016) and enhance their market competitiveness (Sporleder et al. 2011). To that end, SCs arising from RCF platform technologies, hereinafter referred as RCFSCs, could support migration to a modern circular economy (Genovese et al. 2015).

The European Petrochemical Association (McKinnon 2004) and the European Chemicals Industry Council (CEFIC 2015) suggest that improving sustainability in chemical SCs fosters business competitiveness. To this effect, policy initiatives have recently started to promote the exploitation of RCFs as alternatives to fossil fuel-based materials and to support research on enabling entirely new pathways and conversion technologies of potential feedstocks. In the United Kingdom, the Engineering and Physical Sciences Research Council (EPSRC) has recently awarded, through its sustainable chemical feedstocks' initiative, six research grants focusing specifically on RCFs with a total budget of over $£ 12$ million (EPSRC 2012; Tsolakis, Kumar, and Srai 2016). In this vein, the Federal Biobased Products Preferred Procurement Program that is managed by the United States Department of Agriculture requires that agencies procure specific renewable products in order to reduce solid waste streams and decrease costs through contemporarily promoting environmentally favourable alternatives (GIA 2014; USDA 2015). In addition, the United Nations Sustainable Development Summit set 17 Sustainable Development Goals (SDGs) in the document 'Transforming our world: the 2030 Agenda for Sustainable Development' (UNGA 2015), with SDG no. 12 specifically targeting the substantial reduction of waste generation through prevention, reduction, recycling and reuse across SC operations.

However, the development of SC theory and practise based on a portfolio of value-added RCFs is mainly hindered by: (i) the reliance of the chemical industry on vertically integrated feedstock supply systems located in local settings with high yield (Lamers et al. 2015) and (ii) the lack of research upon the technical and commercial feasibility of RCFs' exploitation (Behr and Johnen 2009). Furthermore, utilising RCFs increases the complexity in a SC configuration 
(Srai and Gregory 2008). The mismatch between academic and practitioner language often leads to miscommunication challenges as well (Despeisse et al. 2012). As such, the need for a framework that supports the evaluation of RCF supply networks' configuration opportunities in order to assess their sustainability impact and commercial viability is evident (Tsolakis, Kumar, and Srai 2016).

The present paper presents a theoretically and empirically derived framework to analyse configuration opportunities for RCFSCs, and to articulate key decisions that affect the economic viability, environmentally sustainability and social acceptability of the associated circular supply networks. Our research addresses the following key research questions (RQs):

- RQ1: How should firms navigate viable SC configuration options arising from RCF platform technologies?

- RQ2: What are the key SC related elements that ensure the commercial viability of RCFs defined networks?

The remainder of the paper is structured as follows. In Section 2, we describe the research methodology applied for the purposes of this study. In Section 3, we propose a hierarchical decision-making process for the evaluation of potential RCFSCs and we integrate the identified decisions into a robust framework that supports the networks' viability analysis. Conclusions, limitations and recommendations for future research are discussed in the final Section 4.

\section{Research Methodology}

To address the enunciated RQs, we first reviewed the SC management literature to identify different perspectives from which supply networks are analysed and differentiated, and define any underlying network configuration patterns for different SC analysis perspectives. Table 1 briefly summarises selected publications according to the primary analysis area of the investigated supply networks. Notably, our search revealed a lack of studies providing any 
clear categorisation of SC networks. Rather, the initial findings reveal that traditional theory considers supply networks mainly from a focal company and product-level view-points. In this regard, RCFSCs imply the need to extend the scope of traditional SC theory and understand the way RCFs enable network configurations by linking supply network and value chain concepts with technology and market specifications (Srai, Harrington, and Tiwari 2016). We then draw on the relevant literature to increase our understanding about the emerging RCF defined value chains. Srai (2017) documents that the analysis of emerging industrial SCs needs to capture the following elements to harness value: (i) material transformations from raw material substrates to intermediates and final products, (ii) production processes and technologies and (iii) market actors along with industrial and institutional stakeholders.

Table 1. Main SCs' classification by area of analysis.

\begin{tabular}{|c|c|}
\hline Primary Research Scope & Selected References \\
\hline Company & $\begin{array}{l}\text { Addo-Tenkorang, Helo, and Kantola (2017); Azevedo, Carvalho, and Cruz } \\
\text { Machado (2011); Chen and Wu (2013); Chen, Cheng, and Huang (2013); Cheng } \\
\text { and Wang (2016); Fahimnia et al. (2013); Fisher (1997); Hasani and Khosrojerdi } \\
\text { (2016); Jayaram, Dixit, and Motwani (2014); Johnson and Mena (2008); Khan, } \\
\text { Christopher, and Burnes (2008); Lambert and Cooper (2000); Lamming et al. } \\
\text { (2000); Oke and Gopalakrishnan (2009); Pagell and Wu (2009); Tuncel and } \\
\text { Alpan (2010) }\end{array}$ \\
\hline Industrial System & Blos et al. (2009); Dadhich et al. (2015); Kumar et al. (2013) \\
\hline Product & $\begin{array}{l}\text { Aramyan et al. (2007); Bevilacqua, Ciarapica, and Giacchetta (2009); Bottani et } \\
\text { al. (2015); Bustamante and Gaustad (2014); Choi and Hong (2002); Kulak et al. } \\
\text { (2016); Kumar et al. (2013); Michelsen, Fet, and Dahlsrud (2006); Mirabella, } \\
\text { Castellani, and Sala (2014); Naso et al. (2007); Yue, Kim, and You (2013); } \\
\text { Zhang, Ji, and Fan (2013) }\end{array}$ \\
\hline Technology & Aqlan and Lam (2016); Bergesen and Suh (2016); Srai (2010) \\
\hline
\end{tabular}


In this sense, the theoretical lens on the design, analysis and management of supply networks defined by RCFs should focus on: (i) renewable feedstocks (Böhmer et al. 2012), (ii) feedstock processing technologies and chemical synthesis routes (Xu et al. 2012) and (iii) markets for intermediates or end-products (Behr and Johnen 2009). The aforementioned triplet 'renewable feedstock - technology - market' (Black et al. 2016) has to be coupled with the dimension of commercial 'value and viability' for large-scale implementation in order to accomplish the transition from a fossil-based economy to an ecological - circular - economy (Paulo, BarbosaPóvoa, and Relvas 2013).

Concluding, the analysis of RCFSCs should be based on four interconnected and mutually interacting theme areas, namely 'renewable chemical feedstock - technology - market - value and viability'. Following Tsolakis et al. (2014), the analysis roadmap pursued in this study to devise an analysis framework for RCFSCs is based upon a key decision-making process which is further integrated at each of the four identified analysis areas, as depicted in Figure 1.

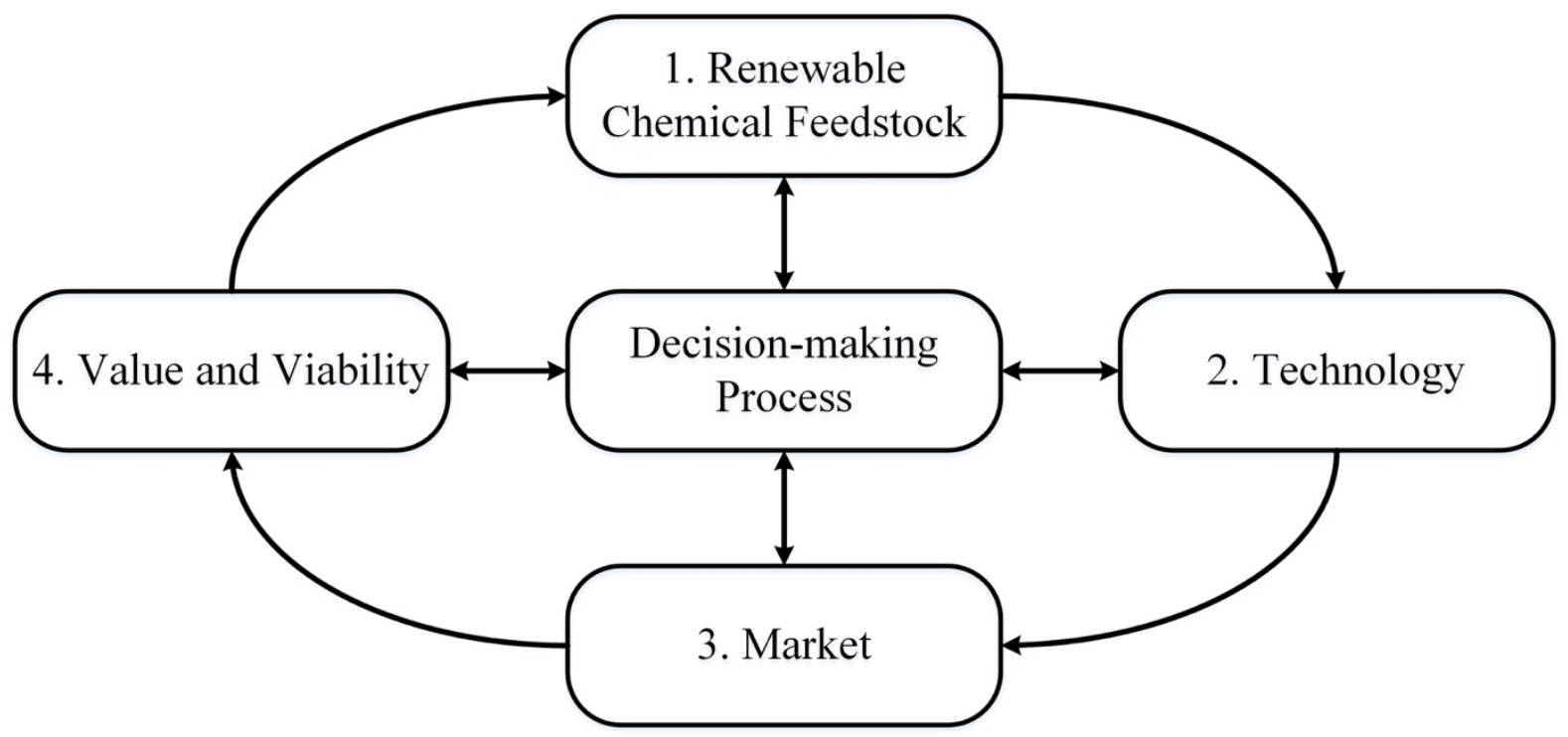

Figure 1. Analysis roadmap for RCF defined supply networks. 


\subsection{Decision-making Process}

The parameters that may inform the proposed decision-making approach are grounded on a synthesis of the existing literature that involves scientific publications for addressing the defined research questions (Levy and Ellis 2006). To identify relevant papers, Boolean searches using appropriate keywords in the Scopus ${ }^{\circledR}$ of Elsevier and Web of Science ${ }^{\circledR}$ of Thomson Reuters databases were performed as they offer a broad range of peer-reviewed journals in the fields of Natural Sciences and Engineering (Mongeon and Paul-Hus 2016). The terms 'renewable feedstock' and 'renewable chemical feedstock' were searched either separately or in combination with the terms 'supply chain', 'supply network', 'supply chain design' and 'supply chain management' using either the 'Article Title' or 'Article Title, Abstract, Keywords' categories. The data range was set from 'All years' to 'Present', while all document types and subject areas were selected. After an initial examination of the publications' content, collected articles were accepted or rejected for further review. More specifically, the analysis was restricted to publications that focus on SC design and management that are written in the English language, while the retrieved journal papers were counterchecked to increase consistency. Notably, we could not retrieve any scientific publications focusing on the design and management of value chain networks defined by RCFs. To that end, we continued our research emphasising on publications that focus on the narrow field of renewable feedstock-based supply networks.

The utilised methodology research steps for developing the proposed decision-making framework for the analysis of RCFSCs is illustrated in Figure 2 through the corresponding flowchart. The methodology pursued incorporates the previously described research steps and is based on a three-tier abstraction process, including: (1) identification of SC classifications, (2) identification of the theme areas to analyse RCFSCs and (3) identification of related decision variables. 


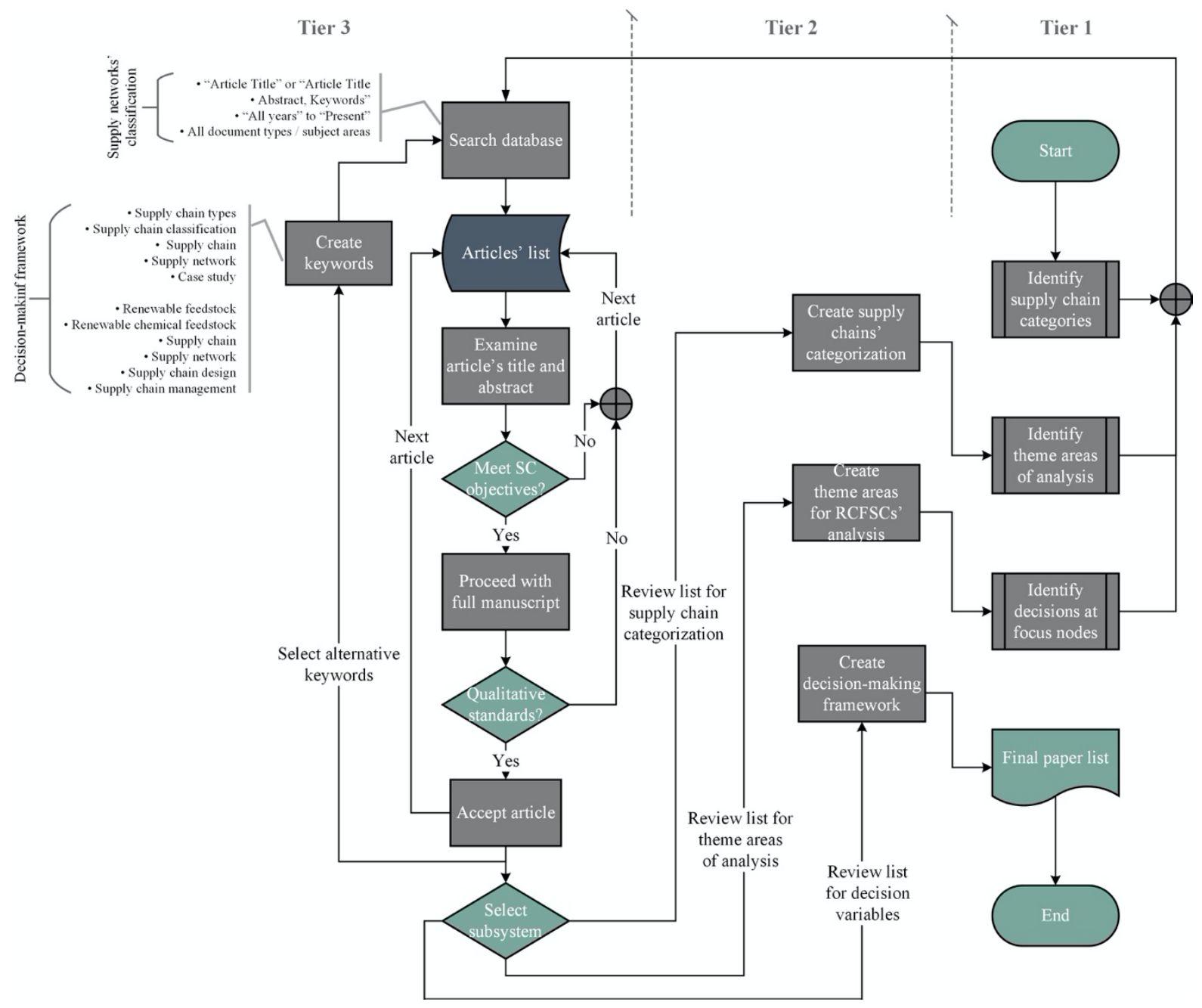

Figure 2. Flowchart of the pursued research methodology.

By 16 August 2016, a total of 53 articles concerning renewable feedstocks and SC design and management had been identified. Figure 3 depicts the annual allocation of the retrieved publications. Although the research period was not restricted, the first published work is detected in 2009. Notably, an increasing number of related articles was published during the period 2012-2016, hence highlighting the growing interest in the field. Likewise, Figure 4 illustrates the distribution of the papers by journal.

The collected journals cover a broad range of scientific areas, such as environmental sustainability, energy systems, chemical engineering and transportation. Nevertheless, the 
distribution of the publications is quite uneven given that journals regarding energy systems account for the majority of the articles included in the synthesis, indicating the dominant role of renewable feedstocks on bioenergy and biofuels' generation in the rapidly advancing field of renewable feedstock-based supply networks. In addition, we observe that the reviewed research works predominately analyse region-specific case studies further demonstrating the practical applicability of the proposed analysis approaches (Sharma, Ingalls, Jones, Khanchi 2013).

Total Number of Papers, $\mathrm{N}=53$

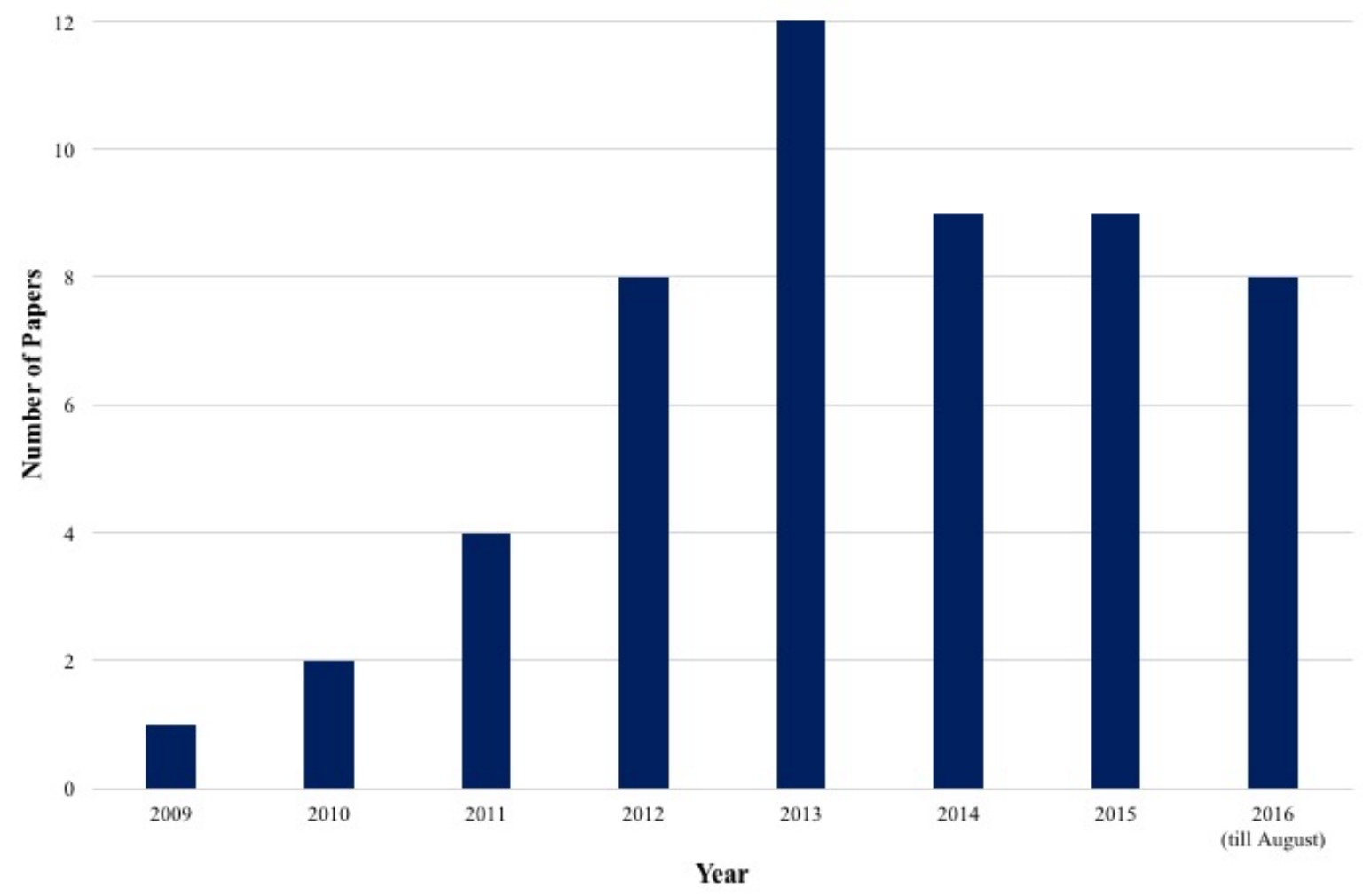

Figure 3. Distribution of publications by year. 
Total Number of Papers, $\mathrm{N}=53$

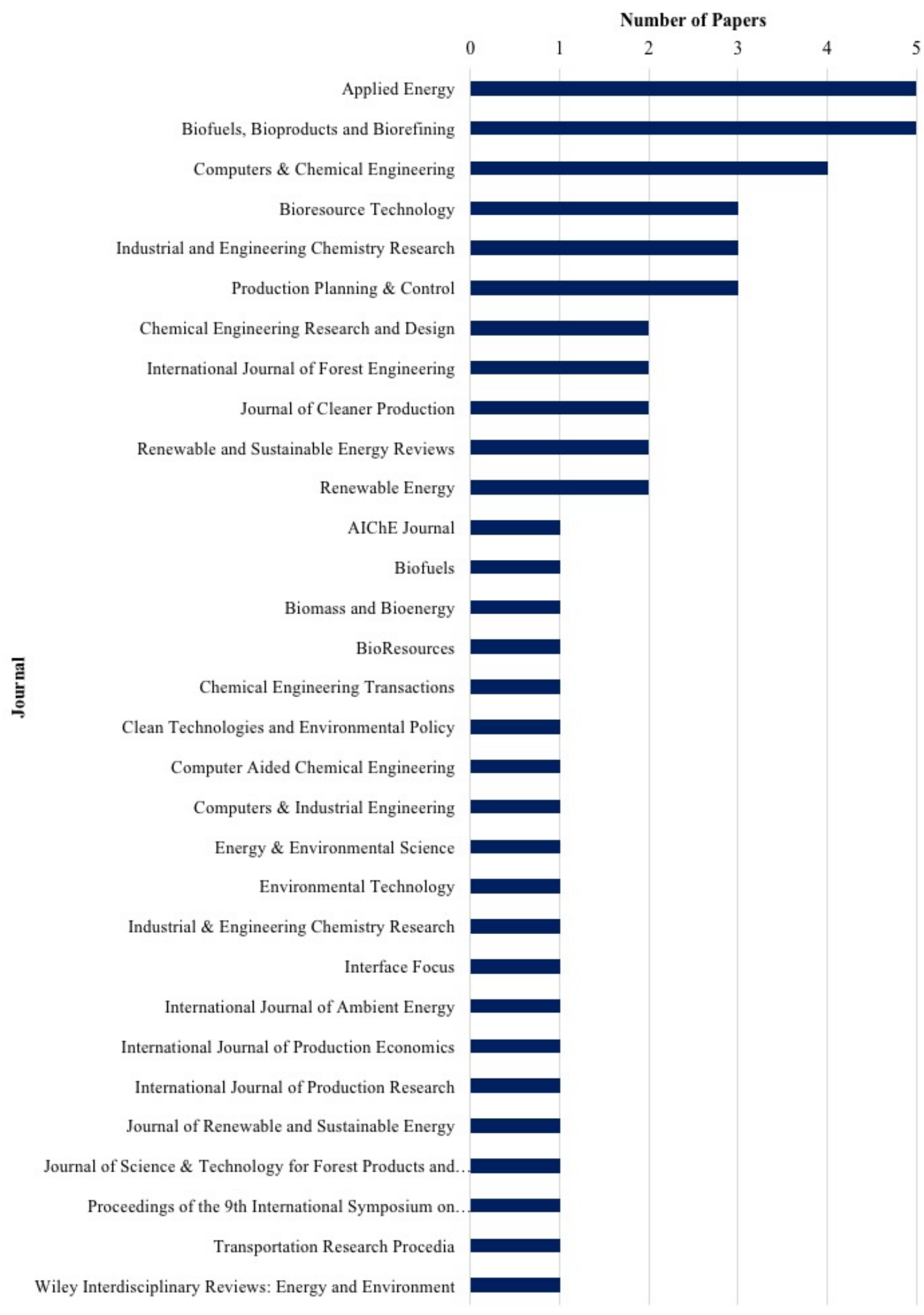

Figure 4. Distribution of publications by journal. 


\subsection{Empirical Research}

The analysis framework for RCFSCs is theoretically grounded on the 'renewable chemical feedstock - technology - market - value and viability' analysis areas. The decisions at each point become critical and involve subject matter expert inputs. After several interview iterations, a multi-stakeholder workshop served to refine the collective outputs and validate the proposed RCFSC analysis framework. Overall, 14 interviews with industry experts affiliated to distinct universities were conducted. The selection of the experts was based upon their longterm involvement in empirical and experimental research related to RCFs and SC management. The interviewed experts' field of specialisation is the following: (i) chemistry - three experts, (ii) biology and bio-chemistry - one expert, (iii) chemical engineering - four experts, (iv) RCFs - three experts, (v) pharmaceuticals - one expert and (vi) systems engineering - two experts. The key points expressed by the interviewees are inserted in Table A1 in the Appendix 1.

More particularly, the experts were initially classified into two groups, as depicted in Figure 5, and the interviews were structured accordingly to harness the experts' experiences and gain insights at two levels: (i) the technical and technology level, i.e. technology and market theme areas and (ii) the systems engineering level, i.e. RCF and value and viability analysis areas. A final workshop involving all experts was organised to build consensus and triangulate the data gathered during secondary research and interviews. Both interviews and the workshop were organised as part of our research within the context of the EPSRC project 'Terpene-based Manufacturing for Sustainable Chemical Feedstocks' (EPSRC Reference: EP/K014889/1). 


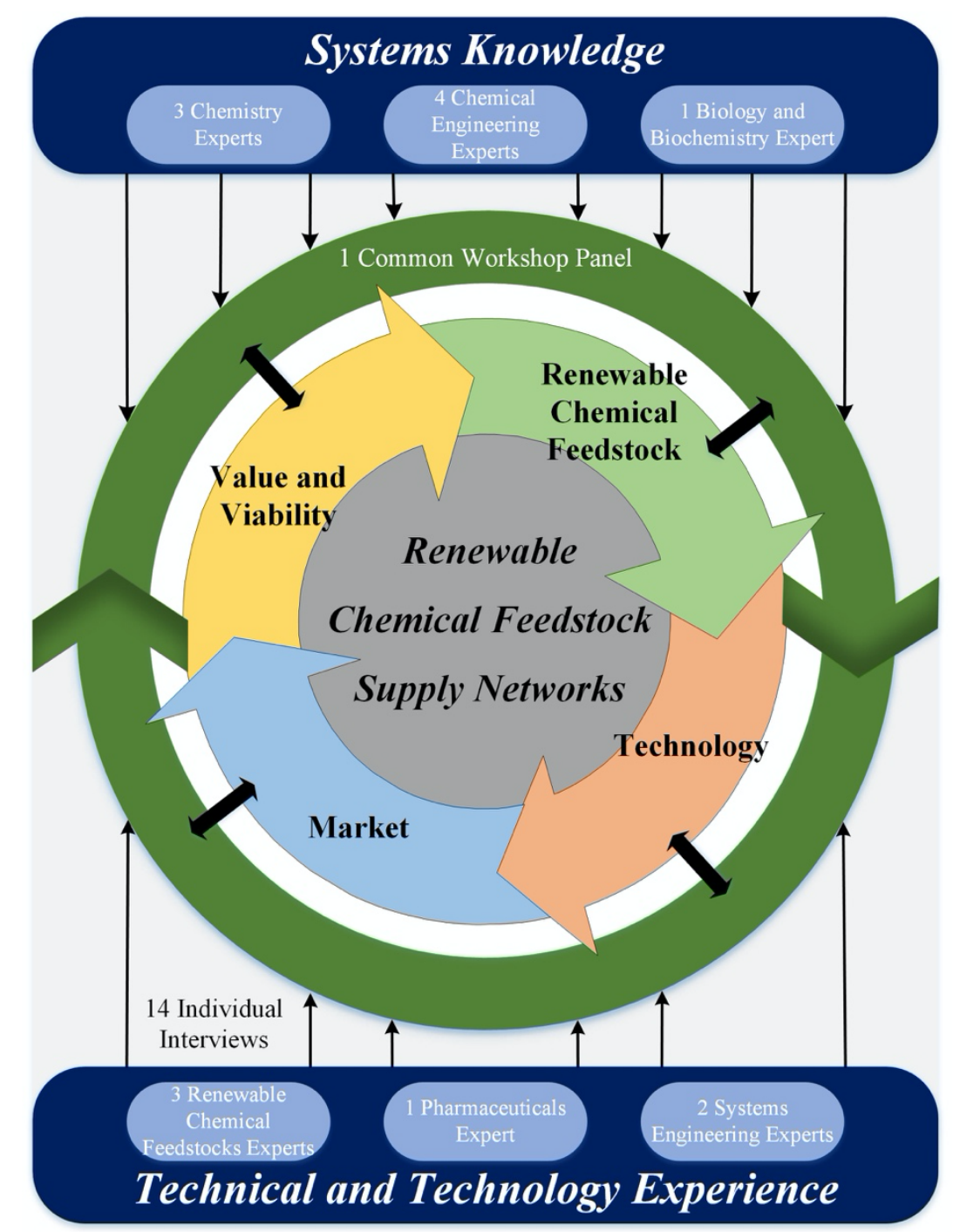

Figure 5. Schematic representation of empirical research.

In this research, we develop industrial and supply network emergence models. More specifically, in this paper we focus on the exploration of terpenoid feedstocks as a case example. Terpenes are based on multiples of C5 isoprene monomer units (Behr and Johnen 2009) and are considered high value-added chemicals for the food, cosmetics, pharmaceuticals and biotechnology industries (Augustin et al. 2011; Thimmappa et al. 2014). However, the wider potential of terpenes as RCFs has been only recently recognised (Behr and Johnen 2009) and their study from a perspective is still lacking. Harnessing the research potential of terpenes is particularly significant as recent advances in technology have enabled entirely new 
processing pathways. The similarity of terpenes to unsaturated hydrocarbons (Behr and Johnen 2009) along with their potential to not compete with food production (Behr and Johnen 2009) also contribute to the attractiveness of studying terpenes as renewable feedstocks for the chemical industry.

The development of the RCFSCs' analysis framework is under- pinned by literature and experts working on the specific field of terpenes. The latter represent a considerable share of the available expertise on the RCFs' research domain, internationally. Additionally, in the empirical research panel we involved experts who had been successful in half of the projects granted by EPSRC aiming to promote the scientific and industrial potential of RCFs

\section{Results and Discussion}

In this section, we first present the results of the investigative method identifying key decision-making parameters for each identified theme area - RCF, technology, market, value and viability - for devising RCFSCs. The decision-making process is followed by the analysis framework for exploring configuration opportunities for RCFSCs.

\subsection{Decision-making Process}

Based on an extensive synthesis of the literature, we provide a generic template of the major decisions in designing RCFSCs. The decision-making process is presented in Table 2. This process does not present an exhaustive list of all relevant decisions, but rather acts as a synthesis of all decisions that we have identified as part of our ongoing research. Below, we briefly discuss the main involved decisions at each analysis area. The decision-making process presented clearly documents the multidimensional character and complex nature of RCFSCs as well as the challenges that have to be addressed for their design and management. 
Table 2. Decision-making process for configuring SCs defined by RCF platform technologies.

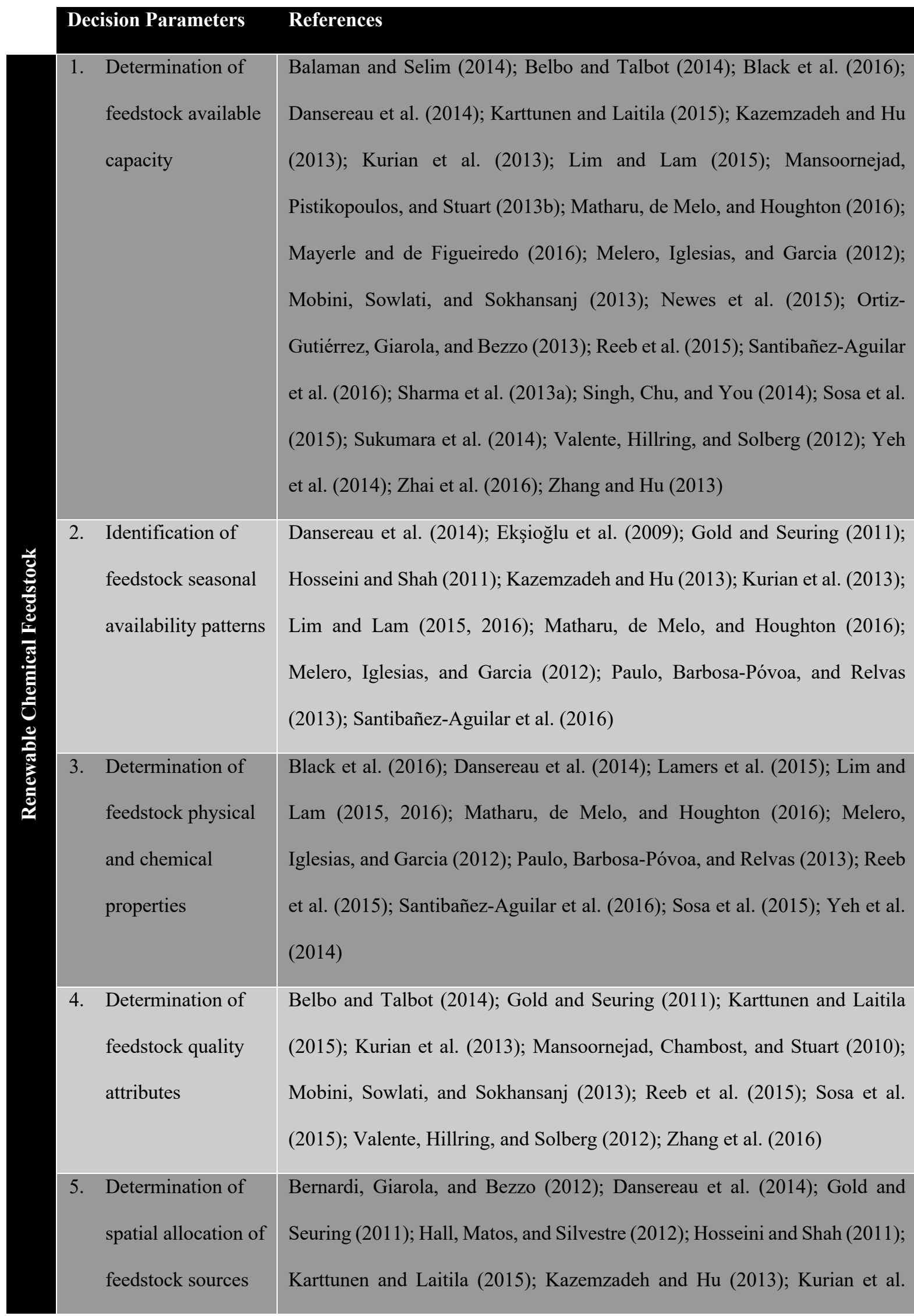




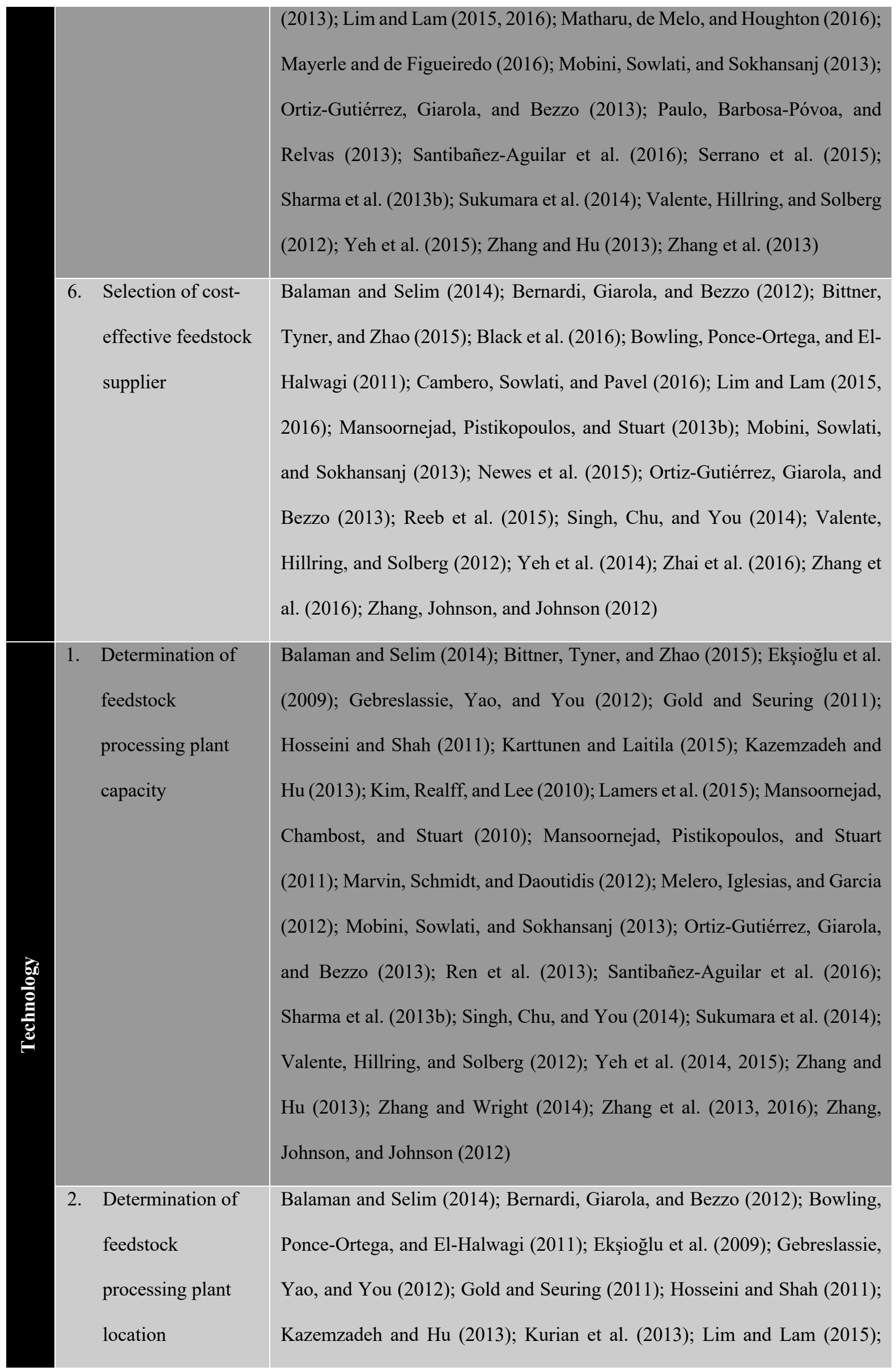




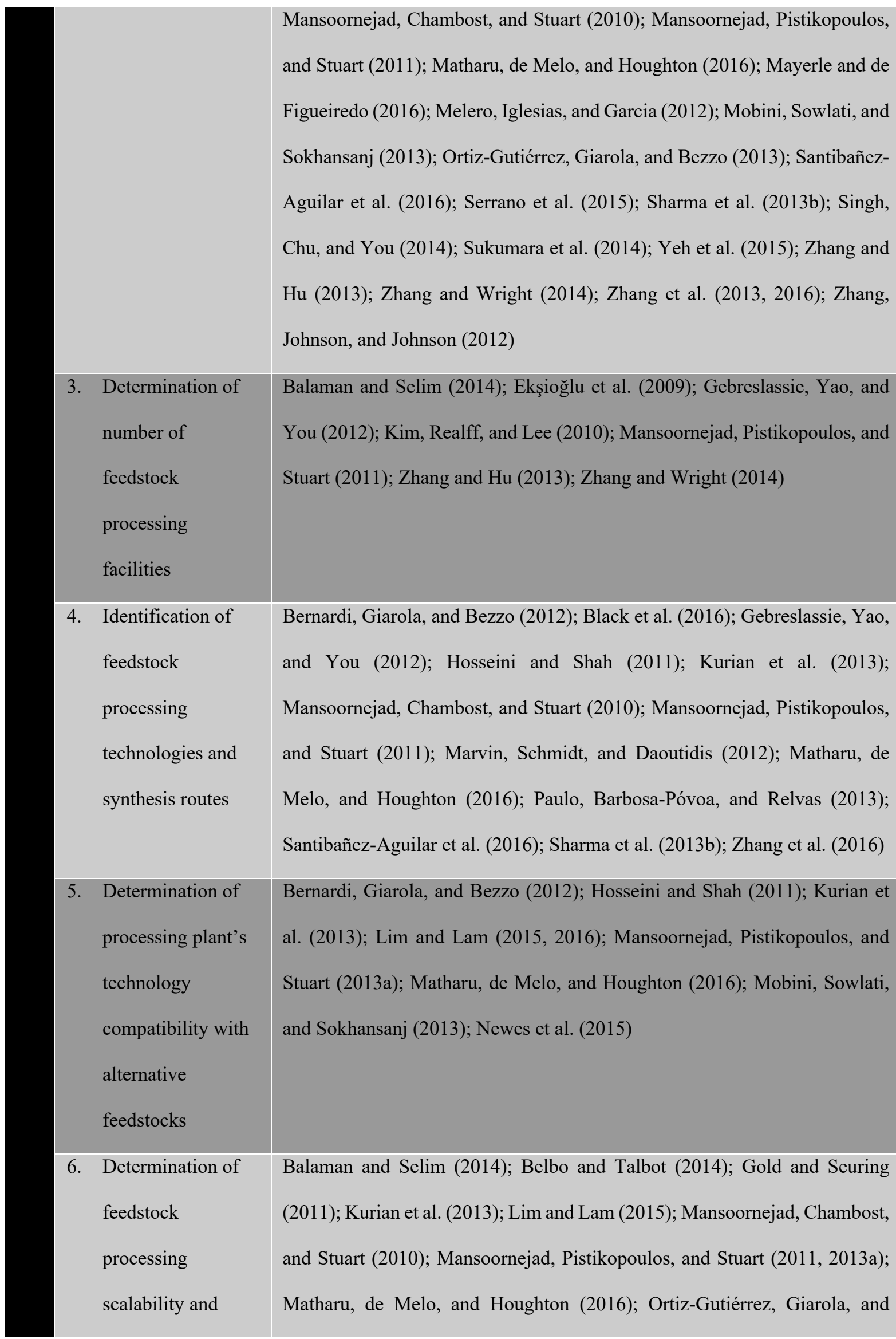




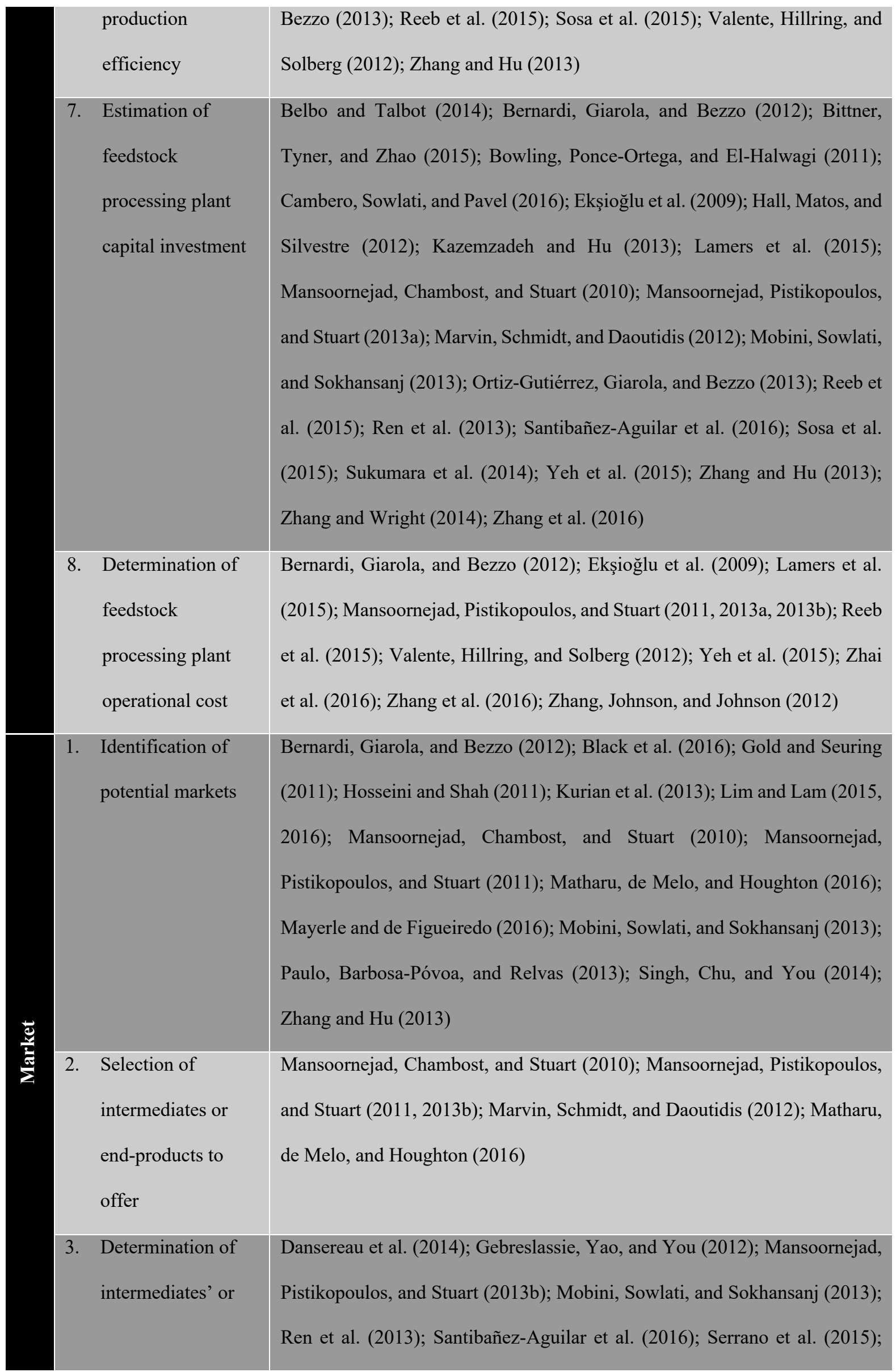




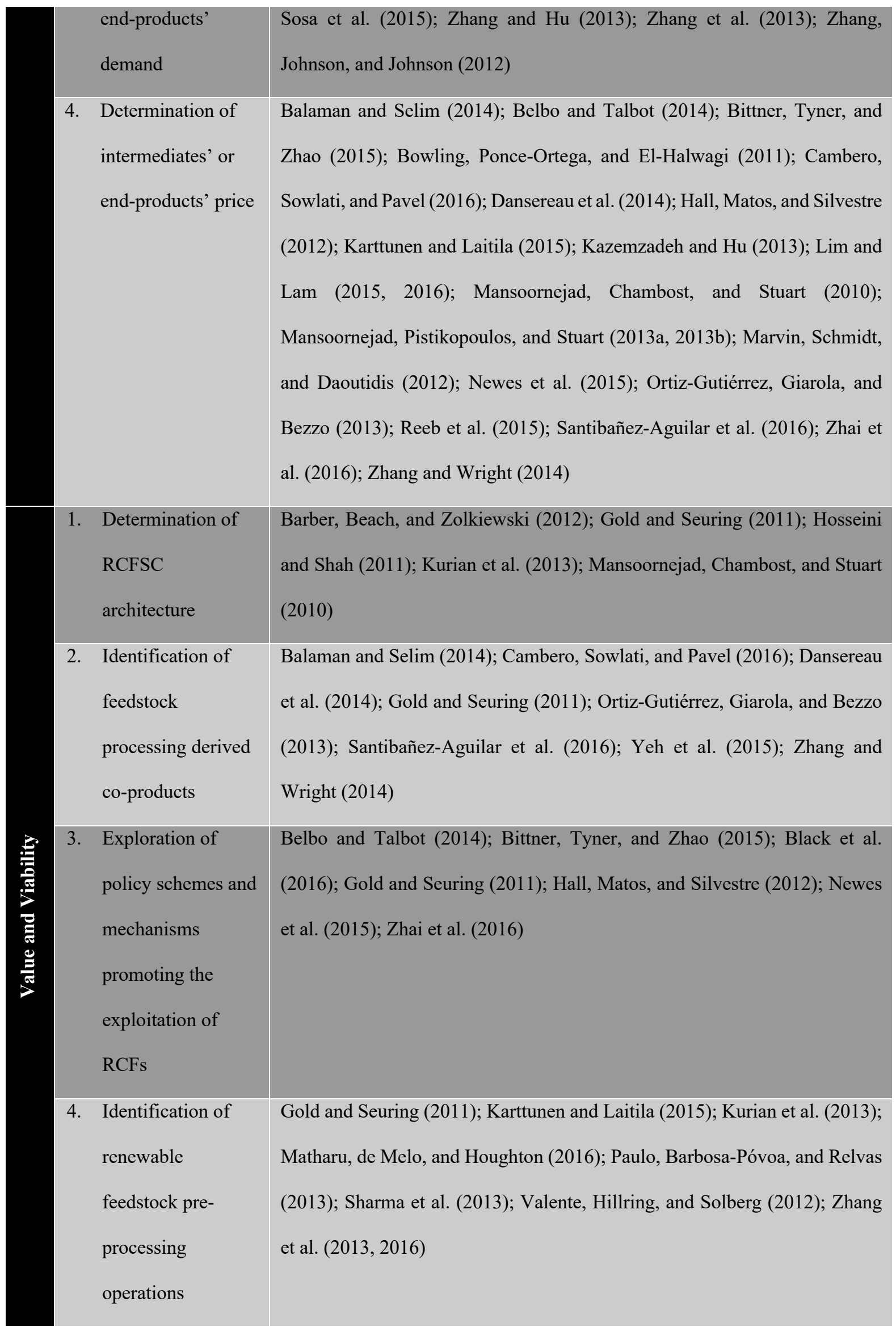




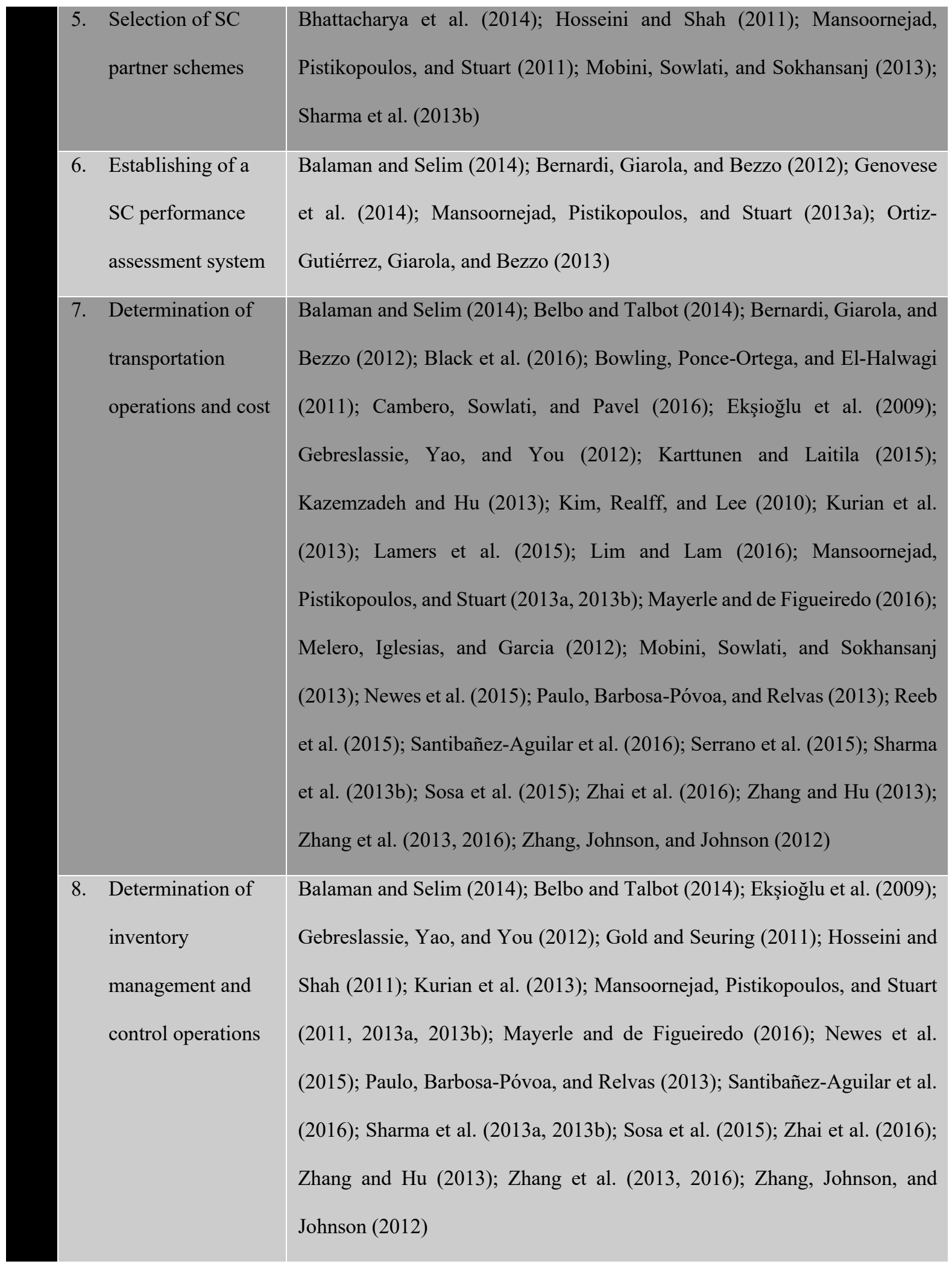




\subsubsection{Renewable Chemical Feedstock}

Renewable feedstocks are increasingly regarded as important sources of sustainable raw materials with the potential to alleviate the reliance on petroleum. Typical barriers related to RCFs are reported to be: (i) quality attributes (DOE 2016), (ii) seasonal availability (CastilloVillar, Minor-Popocatl, and Webb 2016) and (iii) supply costs and price variability (Rentizelas, Tolis, and Tatsiopoulos 2009). Other factors include geographical locations of sources, preprocessing requirements and regulatory implications. In Section 3.1.1.1 through 3.1.1.6, we discuss the key factors that influence the design of supply networks using RCFs.

\subsubsection{Determination of feedstock available capacity}

Feedstock availability ensures the uninterrupted supply of adequate intermediates or endproducts so that a particular supply network can respond to market demand. To this effect, Sharma, Ingalls, Jones, Huhnke, et al. (2013) study the switchgrass supply at Kansas, United States, and reveal that the yield of feedstock is a crucial factor in determining the feasibility of a SC arising from renewable feedstock platform technologies. Similarly, Lim and Lam (2015) tackle the issue of fluctuations in feedstock availability through considering the processing of alternative renewable raw materials that present tolerable physicochemical properties to ensure production consistency and demand fulfilment.

\subsubsection{Identification of feedstock seasonal availability patterns}

The seasonal variations in renewable feedstock availability can have major ramifications to RCFSCs as they directly dictate inventory policies. Indicatively, Melero, Iglesias, and Garcia (2012) stress the discontinued production challenges stemming from the seasonal availability of diverse renewable feedstocks and suggest that existing technologies for converting petroleum-derived raw materials could be also applied to renewable feedstocks on the 
condition that new appropriate catalytic materials are designed to ensure technical compatibility.

\subsubsection{Determination of feedstock physical and chemical properties}

The growing portfolio of available renewable feedstocks which differ in their physicochemical properties imposes that manufacturing technologies and logistics designs need to be determined according to the characteristics of the materials handled. In this context, Lim and Lam (2016) study the energy potential of a range of waste biomass and find that alternative feedstocks could enhance the flexibility of the respective networks in case they present specific bioenergy conversion properties within an acceptable range.

\subsubsection{Determination of feedstock quality attributes}

As the RCF industry grows, concerns are expected to relate to the quality variability of renewable feedstocks due to their impact on the efficiency of subsequent conversion processes. Sosa et al. (2015) model a specific wood biomass SC to satisfy bioenergy demand in Ireland and find that feedstock's moisture content affects the network configuration and cost of the related SC in terms of truckloads' number and haulage needed. Additionally, Valente, Hillring, and Solberg (2012) highlight the significance of feedstock quality in the design and planning of economic and environmental feasible SC operations across the three wood fuel supply network from Norway to the neighbour country of Sweden.

\subsubsection{Determination of spatial allocation of feedstock sources}

The spatial distribution of feedstock supply sources is a key element in designing a RCFSC as it determines the processing plants' configuration and the logistical flows. In this context, Karttunen and Laitila (2015) investigate the essential cost factors for stemwood SCs through 
simulating five forest stands and management regimes in Finland and find that for the case of regions with dense stands energy generation is cost optimal. In addition, Santibañez-Aguilar et al. (2016) study the planning of a distributed SC of biorefineries in Mexico and find that the supply network topology could be affected by the uncertainty in the price of the raw material.

\subsubsection{Selection of cost-effective feedstock supplier}

Feedstock price is interrelated and interdependent with factors such as production location and transportation cost, and affects the commercial viability, cost-effectiveness, and sustainability of the corresponding SC systems. In this vein, Yeh et al. (2014) study the introduction of a biorefinery facility in an established timberlands production system and demonstrated that the decision-makers' behaviour is significantly affected by feedstock price variations. Furthermore, prevalent cost drivers in the bioenergy sector are reported to include the purchasing price of the feedstock and the transportation costs (Reeb et al. 2015), indicating the need to prevent the supply of feedstock from expensive sources (Zhang, Johnson, and Johnson 2012), particularly from regions with volatile weather environments.

\subsubsection{Technology}

The technological aspect should be considered across all three RCFSC operations levels, i.e. upstream (in terms of feedstock volumes from sources to storage facilities and to the preprocessing stage), midstream (in terms of synthesis routes, manufacturing capacity and processing rate), and downstream (spanning from distribution centres to the customer service stations). The related decisions along with a discussion of existing research efforts is provided in the following subsections.

\subsubsection{Determination of feedstock processing plant capacity}


Strategic capacity planning for feedstock processing plants is essential to rationalise capital investments and counterbalance demand uncertainty. Sukumara et al. (2014) demonstrate that medium-scale processing plants could be profitable; however, as the capacity of the plant increases, the capability to process diverse types of renewable feedstock may become challenging due to multiple changeovers. Furthermore, large central facilities will result in increased inbound and outbound transportation costs.

\subsubsection{Determination of feedstock processing plant location}

A generic suggestion in the extant literature is that processing plants are located in areas with high feedstock availability, considering that inbound transportation is a significant cost component. Indicatively, Gebreslassie, Yao, and You (2012) study the design of biorefinery supply networks in the State of Illinois, United States, and demonstrate that lower risk levels can be obtained by shifting the renewable feedstock processing plants from locations with high demand to locations with significant biomass reserves. Furthermore, Bowling, Ponce-Ortega, and El-Halwagi (2011) model the allocation of feedstock pre-processing hubs and biorefineries, and conclude that as the price of the feedstock increases the production/processing facilities are recommended to be located near to feedstock supply sources. Serrano et al. (2015) also comment that the overall SC configuration is affected by the processing plants' capacity. In addition, Zhang, Osmani, et al. (2013) study a comprehensive switchgrass-based bioethanol SC in the State of North Dakota, United States, and find that in case the feedstock processing plants are not optimally located, the total SC cost can increase by $17 \%$, while the resulting transportation cost can increase by up to $400 \%$. 


\subsubsection{Determination of number of feedstock processing facilities}

The growing interest in RCFs reveals that a crucial design parameter for representative value chains is the number of processing plants. In this context, Kim, Realff, and Lee (2010) model biofuel SCs and find that for high market demand a distributed structure for a supply network, comprising of multiple small-scale plants, is preferred as this ensures lower transportation costs and enhanced robustness to demand variations.

\subsubsection{Identification of feedstock processing technologies and synthesis routes}

The choice of renewable feedstocks as alternatives to petrochemical materials has major repercussions in terms of synthesis routes as the required technology or chemical pathways may not yet have been developed. Mansoornejad, Chambost, and Stuart (2010) propose a hierarchical methodology to evaluate product/process portfolio design options, along with the required manufacturing flexibility. Marvin, Schmidt, and Daoutidis (2012) also investigate a portfolio of biomass processing technologies and a series of feedstock types to evaluate the Renewable Fuel Standard mandates set for the year 2015, suggesting technology choice and synthesis route selection may also be driven by compliance to standards.

\subsubsection{Determination of processing plant's technology compatibility with alternative} feedstocks

The opportunities stemming from the plethora of unexplored biochemicals could hedge the supply volatility, seasonal availability and deterioration characteristics of the respective renewable feedstocks. To this effect, Mobini, Sowlati, and Sokhansanj (2013) study the design and analysis of wood pellet SCs from sawdust and shavings and reveal that by changing the mix of feedstocks in the processing plant a decrease in the production cost is observed; however, this case involves a trade-off as it results in increased $\mathrm{CO} 2$ emissions. This 
observation confirms that technology selection is influenced by feedstock choice and multiple performance measures.

\subsubsection{Determination of feedstock processing scalability and production efficiency}

Among the most important technical aspects in the design of RCF industrial systems is the efficiency and upscale capabilities of selected conversion technologies and synthesis routes. Gold and Seuring (2011) provide a systemic review of biomass value chains and discuss that main incentives towards the commercially exploitation of renewable options are: (1) the realisation of economies of scale, (2) the production of multiple and high-valued products and (3) the efficient processing of the input materials.

\subsubsection{Estimation of feedstock processing plant capital investment}

The exploitation of RCFs is still nascent and considerable economic incentives are required to lower capital costs before utilising available feedstocks for value-added industries. In this context, Ekşioğlu et al. (2009) support that the investment in multiple, small-sized biorefineries decreases the overall SC costs by decreasing transportation distances and the corresponding expenditures, specifically estimating that doubling the size of a biorefinery increases the investment cost by a factor of 1.6.

\subsubsection{Determination of feedstock processing plant operational cost}

Currently, the main impediment on the development of renewables for intermediate or endproduct manufacturing is the high cost for processing the available feedstocks. Synthesis routes to extract chemicals from renewable feedstocks are rather at an infancy stage with the increase in capital and operating costs driving the increase in manufacturing flexibility to meet market demand volatility (Mansoornejad, Pistikopoulos, and Stuart 2011). 


\subsubsection{Market}

Potential markets for RCF-based intermediates or end-products are mainly chemicals, organic acids, polymers and resins. A prevalent parameter in the selection of candidate markets is the maturity level or the incipient character of the targeted markets highlighting the practicality of generating market price/demand scenarios and pursuing contractual agreements (Mansoornejad, Pistikopoulos, and Stuart 2011). Below, we set out the key market-related considerations as identified in recent studies.

\subsubsection{Identification of potential markets}

Market identification and conditions dictate competition patterns and shape price formation processes that impact the viability of a supply network. Zhang and $\mathrm{Hu}$ (2013) investigate a general biofuel SC from both strategic and operational levels in the Midwestern Unites States, and conclude that markets with higher shortage penalties and in short distance from the processing facility should be prioritised.

\subsubsection{Selection of intermediates or end-products to offer}

Market identification should be based on a careful market driven analysis reflecting the commercial opportunities for the derived intermediates or end-products. Mansoornejad, Chambost, and Stuart (2010) stress that a product portfolio must be able to stabilise the margins and secure return on investment, while simultaneously considering sustainable partnership models to reduce SC vulnerability (e.g. inferior price substitution or low-volume niche value chains). 


\subsubsection{Determination of intermediates' or end-products' demand}

Demand patterns over the planning horizon of RCFSCs appear to be substantial for the profitability of the network stakeholders. Mansoornejad, Pistikopoulos, and Stuart (2013b) focus on the robustness of renewable feedstock delimited supply networks against different market conditions. They suggest that companies should analyse their access to feedstock, product prices and forecasted demands to find the best alignment between market demand and production capacity to maximise profitability. Moreover, Zhang and $\mathrm{Hu}$ (2013) study the commercial feasibility of biofuel SCs from corn stove in the State of Iowa, United States, and support that the commercialisation of advanced biofuels is advantageous in case the respective demand pattern is steady or increasing over the operational time horizon.

\subsubsection{Determination of intermediates' or end-products' price}

In the domain of RCFs, the sustainable nature of the feedstocks along with the environmental sensitivity of consumers could be leveraged to promote 'green' marketing and foster both demand and price of the provided intermediates or end-products. Kazemzadeh and $\mathrm{Hu}$ (2013) study the optimal design of supply networks for biorefineries in terms of profit by considering uncertainties in fuel market price, feedstock yield and logistics costs in the State of Iowa, United States. The authors find that models that incorporate the expected profit in the objective function provide smaller shortages in the biofuels' market.

\subsubsection{Value and viability}

Developing consistent and economically viable RCFSCs requires embracing alternative feedstocks and addressing diverse transportation scenarios (Zhang, Johnson, and Johnson 2012). In addition, inventory management of both feedstock and intermediates or end-products is essential for ensuring viability. The short availability period of most renewable feedstock 
types along with the often scattered geographical locations of feedstock sources and processing plants induce the need of storage in order to secure the continuity and viability of supply (Gold and Seuring 2011). Additional considerations are set out below.

\subsubsection{Determination of RCFSC architecture}

The need for an integrated value chain and business model is accentuated in the case of RCFSCs as these networks involve different market segments and SC actors, combinations of various feedstock sources, as well as complex conversion approaches and end-use applications (Barber, Beach, and Zolkiewski 2012). Particularly, a major challenge in modelling bioenergy SCs is the supply network's infrastructure and design(HosseiniandShah2011) that is further supported by the literature (e.g. Gold and Seuring 2011). Following another perspective, Lamers et al. (2015) propose an advanced SC architecture for cellulosic biorefineries across the United States that allows access to greater quantities of sustainable feedstock, while in parallel assists in reducing temporal and spatial biomass variability within a cost target.

\subsubsection{Identification of feedstock processing derived co-products}

RCFSCs should provide valuable co-products to ensure fast productivity cycles and market penetration rates in order to enhance SCs' commercial viability. Indicatively, Paulo, BarbosaPóvoa, and Relvas (2013) consider in their modelling approach the co-production of chemicals from a diverse spectrum of feedstock sources through utilising a portfolio of alternative manufacturing processes, while Yeh et al. (2015) conclude that a timber SC system value increases through the exploitation of derived co-products. In this vein, Zhang and Wright (2014) study the optimal SC design for a fast pyrolysis system in Minnesota State, United States, and stress that the network's viability is enhanced in case a portfolio of products are derived during feedstock processing. In addition, Dansereau et al. (2014) support the critical 
role of product/process combinations and differentiated product portfolios for ensuring the long-term competitiveness of forest supply networks with Balaman and Selim (2014) confirming the pivotal role of co-products towards enhancing network viability. OrtizGutiérrez, Giarola,andBezzo(2013) stress the need for ensuring the production of co-products during corn processing in ethanol SCs, while Mayerle and de Figueiredo (2016) demonstrate the applicability of a co-located anaerobic biodigestion unit/energy generation plant with distributed biomass sources in Southern Brazil.

\subsubsection{Exploration of policy schemes and mechanisms promoting the exploitation of RCFs}

Advancing towards a more circular economy and overcoming the RCFSC-associated challenges requires that public policies align with industry motives. Governmental interventions both upstream and downstream a feedstock-to-product network (Newes et al. 2015) along with information sharing and visibility across the triplet 'farmer - biomass power plant - government' (Zhai et al. 2016) are found to be detrimental for devising viable SCs. Hall, Matos, and Silvestre (2012) study the case of Brazilian oil and gas, sugarcane ethanol and biodiesel SCs, and identify the enforcement of governmental regulatory schemes as a critical element in ensuring the deployment of sustainable SCs, while Black et al. (2016) extend the previous findings and conclude that policy support is vital for the leveraging of renewable feedstocks in terms of promoting co-generation markets. Furthermore, Belbo and Talbot (2014) study the performance of straw SCs for the generation of energy in Norway and highlight that the transition from small-scale to large-scale manufacturing based on renewable feedstocks requires a shift in motivation from the purely economic to the legislative and political levels. From an investments' point of view, Bittner, Tyner, and Zhao (2015) analyse the viability of aviation biofuel SCs from corn stove in the Unites States and find that reverse auctions reduce 
the respective risk more efficiently compared to capital subsidies, at the same total cost for the government.

\subsubsection{Identification of renewable feedstock pre-processing operations}

Chemical feedstock pre-processing has significant effects on all downstream SC operations and ultimately influences the overall intermediates' or end-products' yield, quality and cost. Kurian et al. (2013) discuss pre-treatment options for liquid biofuels and biomaterials from lignocellulosic feedstocks and stress that mass balance is the primary parameter impacting the pre-treatment process efficacy. In addition, Matharu, de Melo, and Houghton (2016) stress the need for food waste pre-treatment in order to increase the extraction rate of valuable chemical compounds.

\subsubsection{Selection of SC partnership schemes}

Commercially valuable RCFSCs are established on robust and long-term collaborative relationships. From an economic perspective, studies on bioenergy SCs defined by either biocrops (Singh, Chu, and You 2014) or forest residues (Mansoornejad, Pistikopoulos, and Stuart 2013a) dictate the importance of network consistency and stakeholders' collaborative integration to create value-added supply networks. From an environmental standpoint, cases in both the United Kingdom (Bhattacharya et al. 2014) and China (Ren et al. 2013) discuss the need to apply data flow schemes across SCs to motivate actor compliance to common environmental standards.

\subsubsection{Establishing of a SC performance assessment system}

Real-world practice indicates that managers should insightfully consider the assessment of SC performance in order to ensure an organisation's long-term success. Genovese et al. (2014) 
identify the procurement of renewable/recycled feedstock as a key indicator for supplier performance evaluation, necessary for ensuring the long-term viability of operations for the case of the United Kingdom's fast-moving consumer goods sector. Bernardi, Giarola, and Bezzo (2012) address strategic design issues of multi-period and multi-echelon upstream ethanol SCs in Northern Italy and infer SC investors need to consider the environmental footprint of the related operations to evaluate a sustainable supply network design. Furthermore, Sharma, Ingalls, Jones, Khanchi (2013) provide a comprehensive review of biomass SC design and modelling approaches, and comment that the purpose of the majority of models is cost minimisation and the next most popular performance measure is revenue maximisation.

\subsubsection{Determination of transportation operations and cost}

Transportation and logistics operations in RCFSCs should also provide added value to the customer and in compliance with regulations and predetermined performance criteria. Cambero, Sowlati, and Pavel (2016) study the design of bioenergy and biofuel SCs in British Columbia, Canada, and find that from an environmental perspective the large-scale production of pellets is recommended, while from an economic aspect the production of pellets at a small scale would be preferable to offsetting high capital investments and transportation costs.

\subsubsection{Determination of inventory management and control operations}

Inventory management and control is essential to minimise environmental emissions. Zhang et al. (2016) study potential economic impacts stemming from the deployment of SC operations for three different bioenergy products in the United States, namely: (i) cellulosic ethanol in Iowa, (ii) renewable diesel blendstock in Georgia and (iii) renewable diesel and gasoline blendstock in Mississippi. They express the need of effective inventory management to avoid 
excessive storage costs, matter losses and degradation of raw materials' physicochemical specifications.

\subsection{RCFSCs' viability framework}

Today, SC management goals are oriented towards the eco- nomically feasible integration of environmental concerns into business operations by minimising waste material flows and by improving the sustainability performance of production and consumption systems (Ilić and Nikolić 2016). In this vein, SC management theory has also to consider sustainability drivers within the boundaries of market eco-sensitivity along with environmental and taxation policy schemes, and emphasise the idea of implementing supply systems in which materials are reused. Following the aforementioned goals and drivers, modern SC management can lead towards workable relationships between ecological systems and economic growth signalling the circular economy era (Abdul Nasir et al. 2016), as depicted in Figure 6.

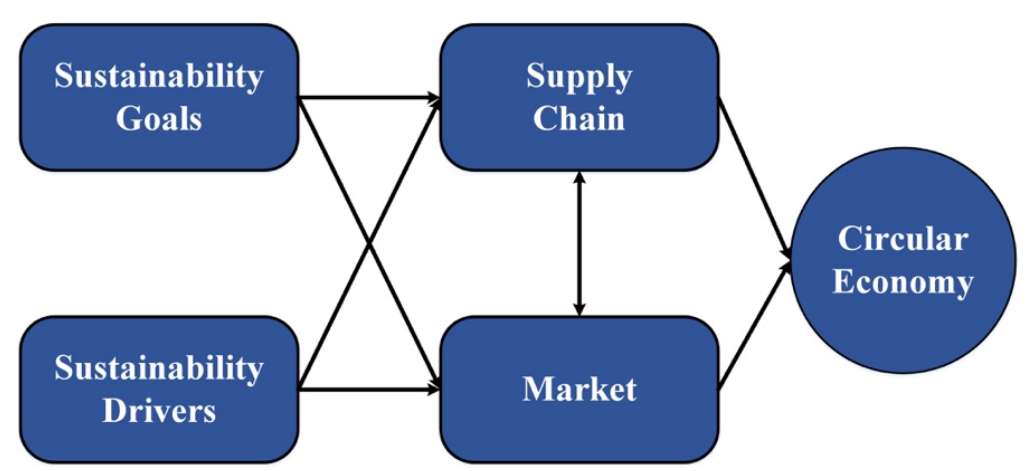

Figure 6. Generic analysis scheme for circular SCs.

Therefore, circular supply network concepts are used to explore alternative RCFSC configuration opportunities, as illustrated in Figure 7. In conventional feedstock SCs, the material flow is linear and unidirectional beginning with the extraction of natural resources and ending with the pollution of the environment with significant waste streams. The paradigm of 
RCFSCs seeks to continually sustain the circulation of waste streams as resources that can replace petrochemical-based raw materials in order to provide value-added intermediates or end-products in existing and nascent markets while reducing the need for additional natural raw material inputs into industrial systems. The resulting SC configuration structure is highly influenced by the feedstock specifications and quality attributes, along with the geographical dispersion of the related sources. Furthermore, technology capabilities and market specificities should be meticulously investigated to ensure the viability of the referred SCs.

For the network designer, seeking to incorporate RCFs into viable product/process options there are a plethora of challenges. Unlike conventional SCs where demand of final products drives the primary analysis, in the case of RCFs the first task begins at the supply of raw materials. In this first theme area, RCF availability and assessment network design must consider renewable feedstocks' demand and price volatility, and substrate selection. Second, we must consider the technology options for the transformation of chosen substrates to useful intermediates. Third, there remains the identification of attractive markets, i.e. the product SCs that might reconfigure to renewable use. Finally, commercial evaluation will require the integration of these previous elements, and combine individual assessments on resource availability, intermediate and end-market SCs, to assess overall commercial viability. From a SC perspective, the theoretical challenge is significant; the demand-driven sequence of activities that drive production and planning should be replaced by a feedstock-driven evaluation that instigates technical and commercial development. In this context, the provided framework aims to enable the systematic exploration of renewable feedstock SCs. 

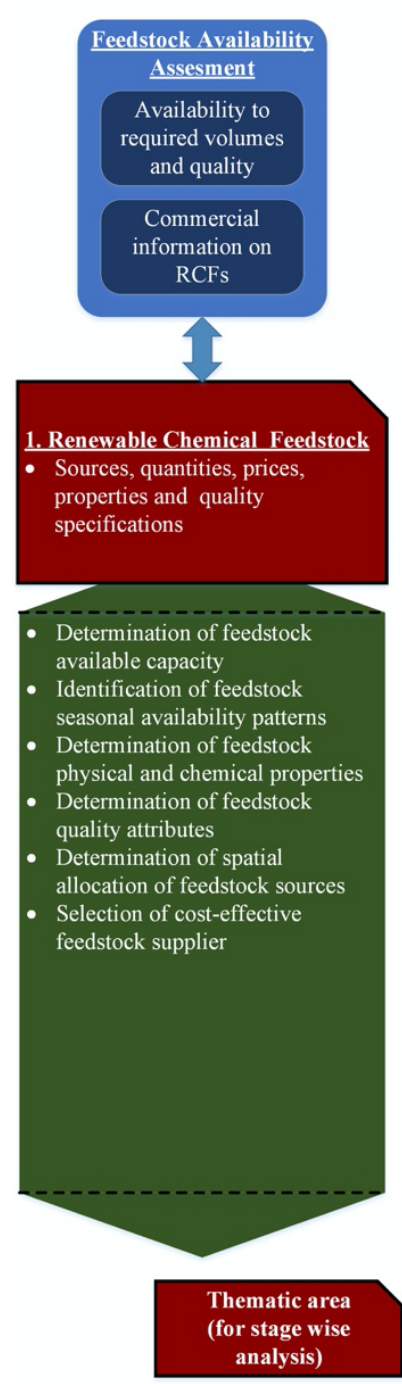
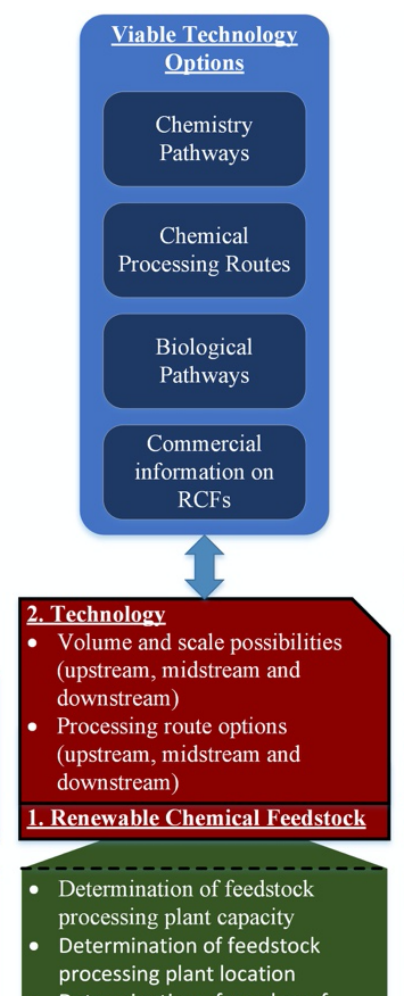

Determination of number of

feedstock processing facilities

- Identification of feedstock

processing technologies and

synthesis routes

- Determination of processing

plant's technology compatibility

with alternative feedstocks

Determination of feedstock

processing scalability and

production efficiency

Estimation of feedstock

processing plant capital

investment

- Determination of feedstock

processing plant operational cost
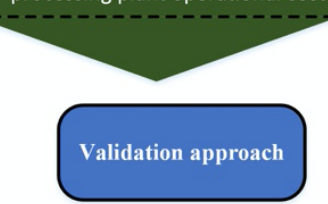

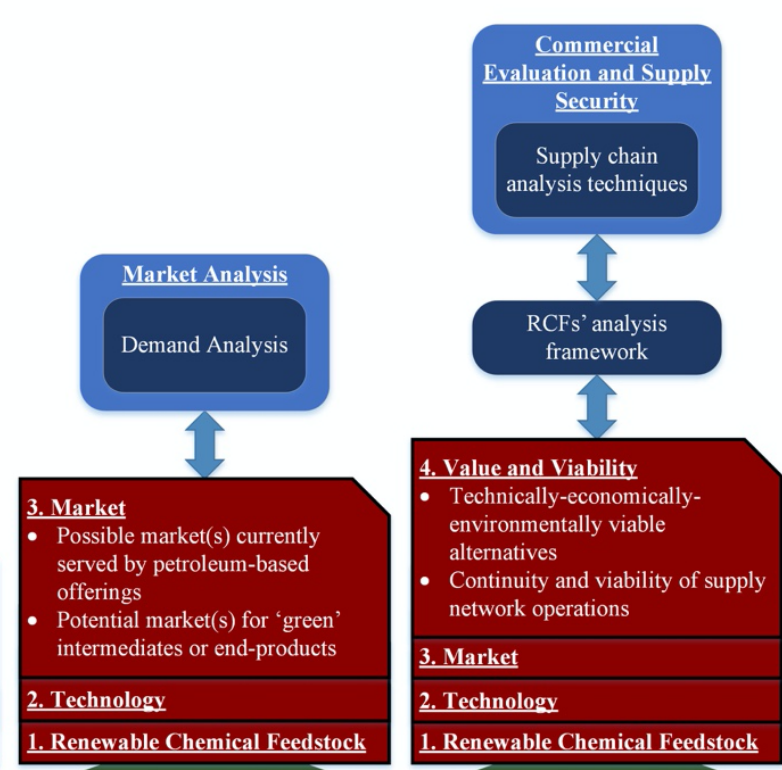

- Identification of potential markets

Selection of intermediates or

end-products to offer

Determination of intermediates'

or end-products' demand

Determination of intermediates'

or end-products' price

\section{Determination of RCFSC \\ architecture \\ - Identification of feedstock \\ processing derived co-products \\ - Exploration of policy schemes}

and mechanisms promoting the

exploitation of RCFs

- Identification of renewable

feedstock pre-processing

operations

- Selection of SC partner schemes

- Establishing of a SC performance

assessment system

- Determination of transportation

operations and cost

- Determination of inventory

management and control

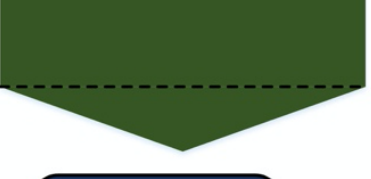

Specific information source operations

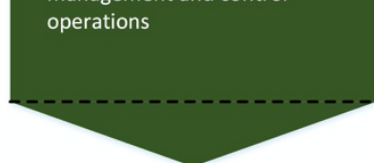

Decision-making parameters

Figure 7. Analysis framework for supply networks defined by RCF platform technologies.

\section{Conclusions}

This research sets out the development process for the systematic evaluation of RCF substrates, intermediates and final products into commercially viable propositions. An RCF platform approach is adopted beginning with a SC assessment on material sourcing options, progressing to final market analysis, reversing the traditional demand-driven SC analysis approach. 
The pursuit of a truly circular economy exerts considerable pressure on the frontiers of environmental sustainability. The approach emphasises the transformation of products in a manner that leads to workable relationships among ecological systems, economic growth and social well-being (Genovese et al. 2015). The transition from petroleum-based feedstocks to renewable alternatives in a viable manner is an example of the circular economy approach as part of sustainable SC management (Walker et al. 2014). Taking into consideration this SC perspective, this paper provides a critical decision-making framework in the RCFs' domain. Specifically, the findings of the synthesis indicate the following insights. First, the extant research reveals that traditional SC analysis techniques are designed for studying value networks from a technology, product, firm or market perspectives, confirming observations from Tsolakis, Kumar, and Srai (2016). In addition, a lack of effective circular SC analysis tools is evident; as a result, the potential to use industrial waste streams is often not exploited. Secondly, our synthesis indicates that the availability and the unique properties of RCFs, available from diverse industrial sources, have long-term viability. RCFs can be used for both established or niche business activities (Lim and Lam 2016). Nevertheless, we find that chemical complexity and upscaling potential of manufacturing output are fundamental challenges for the valorisation of RCFs (Tuck et al. 2012). Thirdly, considering the complex trade-offs involved among competing SC and logistics decisions that affect the sustainable performance of renewable feedstock-based supply networks, integrated management and optimisation of all the individual components along the entire value chain is essential (Zhang, Osmani, et al. 2013).

As RCFs are intertwined with SC design and management considerations, the implementation of a robust decision-making process across emerging circular SCs is necessitated (Tsolakis, Kumar, and Srai 2016). In this context, this paper contributes to sustainable SC research by investigating SC designs based on renewable materials. In 
particular, we adapt existing technology, product, firm or market-defined SC analysis techniques to the domain of compound class-defined SC analysis and we lay the foundations for quantitative economic and environmental modelling of RCF-based networks. The proposed framework aims at capturing the most relevant design variables for the configuration of viable RCFSCs, which is mainly motivated by scientific publications on bioenergy and biofuels' sectors according to our research. We argue from theory and a synthesis of extant empirical studies that stakeholders should explore alternative SC configuration options based on specific RCFs and tackle in sequence key decisions regarding feedstock availability, enabling technologies for producing target intermediates, and potential markets of the derived intermediates or end-products. Furthermore, for designing commercially viable SCs evidence from both qualitative and quantitative data with regards to feedstock quality specifications, geographic location of feedstocks and conversion plant operations, synthesis routes and manufacturing capacity, inventory planning and logistics operations should be, as per our framework, systematically gathered and analysed.

The framework developed in this paper can be usefully applied in primary industries such as chemicals and related industries such as active pharmaceutical ingredient (API) manufacture (Kawaguchi et al. 2016). More specifically, terpenes, a large and diversified class of hydrocarbons available in plant biomass and industrial waste, can be leveraged as sources of RCFs to pro- vide substitutes to petroleum-based equivalents for a range of applications (Wu and Davis 2016). Indicatively, as part of our ongoing research we investigate the case of 'green' paracetamol synthesised from terpenoid feedstocks using waste from pulp digestion in Kraft paper mills (Tsolakis and Srai 2016, 2017). This circular economy paradigm can inform an integrated assessment approach where the analysis of feedstock sources, processing technologies and resulting intermediates or end-products can be undertaken in a systematic manner. 
In conducting this study, some limitations are evident which provide interesting grounds for expanding our research horizons. Firstly, the provided analysis framework was developed using an extensive literature review, while testing and refinement was restricted to input from academic experts involved in interviews. Primary industry related data may provide greater insights into the decision-making process of configuring supply networks defined by RCFs and would facilitate validation and generalisability of the provided findings. Secondly, this study is positioned at a conceptual and process level, but does not quantify cost and lead time considerations resulting from specific geographical location decisions.

With respect to future scientific directions, we anticipate the progress of the research in the field of RCFSCs. More specifically, we aim to demonstrate the applicability of the proposed RCFSC framework on real-world settings (Balaman and Selim 2016), initially through the case of terpenes and latter via other specific waste - feedstock - streams, as paramount for understanding, designing and optimising the operations of the respective end-to-end supply networks. To date, the extant literature appears to have resulted in an over emphasis on biomass development for bioenergy generation, meaning that existing studies have largely not considered other renewable feedstocks for the chemical industry. This research could promote the development of a novel methodology for combining and evaluating available RCFs across industries in order to foster the economic viability of the chemical sector and to ensure overall environmental performance (Čuček et al. 2015). As such, considering the reuse of promising organic (Li et al. 2015) and inorganic (Nasir et al. 2017) waste streams into value-added commodities, this research informs the development of a comprehensive approach for assessing sustainable policy interventions in support of robust assessment of emerging circular supply networks. 
Disclosure statement. No potential conflict of interest was reported by the authors.

Acknowledgments. This research has received funding from the EPSRC Reference No. EP/K014889/1 - "Terpene-based Manufacturing for Sustainable Chemical Feedstocks", and the EPSRC Reference No. EP/K02888X/1 - "Engineering Driven Sustainable Supply Networks".

\section{References}

Abdul Nasir, M. H., Genovese, A., Acquaye, A. A., Koh, S. C. L., and F. Yamoah. 2016. "Comparing linear and circular supply chains: A case study from the construction industry." International Journal of Production Economics 183 (Part B): 443-457.

Addo-Tenkorang, R., Helo, P. T., and J. Kantola. 2017. “Concurrent enterprise: A conceptual framework for enterprise supply-chain network activities." Enterprise Information Systems 11 (4): 474-511.

Anuar, M. R., and A. Z. Abdullah. 2016. "Challenges in biodiesel industry with regards to feedstock, environmental, social and sustainability issues: A critical review." Renewable and Sustainable Energy Reviews 58: 208-223.

Aqlan, F., and S. S. Lam. 2016. "Supply chain optimization under risk and uncertainty: A case study for high-end server manufacturing." Computers \& Industrial Engineering 93: 7887.

Aramyan, L. H., Lansink, A. G. J. M. O., van der Vorst, J. G. A. J., and O. van Kooten. 2007. "Performance measurement in agri-food supply chains: A case study." Supply Chain Management: An International Journal 12 (4): 304-315.

Augustin, J. M., Kuzina, V., Andersen, S. B., and S. Bak. 2011. "Molecular activities, biosynthesis and evolution of triterpenoid saponins." Phytochemistry 72: 435-457. 
Azevedo, S. G., Carvalho, H., and V. Cruz Machado. 2011. "The influence of green practices on supply chain performance: A case study approach." Transportation Research Part E: Logistics and Transportation Review 47 (6): 850-871.

Balaman, Ş. Y., and H. Selim. 2016. "Sustainable design of renewable energy supply chains integrated with district heating systems: A fuzzy optimization approach.” Journal of Cleaner Production 133: 863-885.

Balaman, Ş. Y., and H. Selim. 2014. "A network design model for biomass to energy supply chains with anaerobic digestion systems." Applied Energy 130: 289-304.

Barber, K. D., Beach, R., and J. Zolkiewski. 2012. "Environmental sustainability: a value cycle research agenda.” Production Planning \& Control 23 (2-3): 105-119.

Bhattacharya, A., Mohapatra, P., Kumar, V., Dey, P. K., Brady, M., Tiwari, M. K., and S. S. Nudurupati. 2014. "Green supply chain performance measurement using fuzzy ANPbased balanced scorecard: A collaborative decision-making approach." Production Planning \& Control 25 (8): 698-714.

Behr, A., and L. Johnen. 2009. "Myrcene as a natural base chemical in sustainable chemistry: a critical review." ChemSusChem 2 (12): 1072-1095.

Belbo, H., and B. Talbot. 2014. "Performance of small-scale straw-to-heat supply chains in Norway." Wiley Interdisciplinary Reviews: Energy and Environment 3 (4): 400-407.

Benchaita, T. 2013. "Greenhouse gas emissions from new petrochemical plants: Background information paper for the elaboration of technical notes and guidelines for IDB projects." Technical Note No. IDB - TN - 562. Washington, DC: Inter-American Development Bank, Environmental Safeguards Unit.

Bergesen, J. D., and S. Suh. 2016. “A framework for technological learning in the supply chain: A case study on CdTe photovoltaics." Applied Energy 169: 721-728. 
Bernardi, A., Giarola, S., and F. Bezzo. 2012. "Optimizing the economics and the carbon and water footprints of bioethanol supply chains." Biofuels, Bioproducts and Biorefining 6 (6): 656-672.

Bevilacqua, M., Ciarapica, F. E., and G. Giacchetta. 2009. "Business process reengineering of a supply chain and a traceability system: A case study." Journal of Food Engineering 93 (1): 13-22.

Bittner, A., Tyner, W. E., and X. Zhao. 2015. "Field to flight: A techno-economic analysis of the corn stover to aviation biofuels supply chain." Biofuels, Bioproducts and Biorefining 9: 201-210.

Black, M. J., Sadhukhan, J., Day, K., Drage, G., and R. J. Murphy. 2016. “Developing database criteria for the assessment of biomass supply chains for biorefinery development." Chemical Engineering Research and Design 107: 253-262.

Blos, M. F., Quaddus, M., Wee, H. M., and K. Watanabe. 2009. "Supply chain risk management (SCRM): A case study on the automotive and electronic industries in Brazil.” Supply Chain Management: An International Journal 14 (4): 247-252.

Böhmer, N., Roussière, T., Kuba, M., and S. A. Schunk. 2012. "Valorisation of glycerol as renewable feedstock: Comparison of the exploration of chemical transformation methods aided by high throughput experimentation." Combinatorial Chemistry \& High Throughput Screening 15 (2): 123-135.

Bottani, E., Montanari, R., Rinaldi, M., and G. Vignali. 2015. "Modeling and multi-objective optimization of closed loop supply chains: A case study." Computers \& Industrial Engineering 87: 328-342.

Bowling, I. M., Ponce-Ortega, J. M., and M. M. El-Halwagi. 2011. "Facility location and supply chain optimization for a biorefinery." Industrial \& Engineering Chemistry Research 50 (10): 6276-6286. 
Brown, T., Gambhir, A., Florin, N., and P. Fennell. 2012. "Reducing $\mathrm{CO}_{2}$ emissions from heavy industry: A review of technologies and considerations for policy makers." Grantham Institute for Climate Change - Briefing Paper No 7. London: Imperial College London.

Bustamante, M. L., and G. Gaustad. 2014. "Challenges in assessment of clean energy supplychains based on byproduct minerals: A case study of tellurium use in thin film photovoltaics.” Applied Energy 123: 397-414.

Cambero, C., Sowlati, T, and M. Pavel. 2016. "Economic and life cycle environmental optimization of forest-based biorefinery supply chains for bioenergy and biofuel production." Chemical Engineering Research and Design 107: 218-235.

Castillo-Villar, K. K., Minor-Popocatl, H., and E. Webb. 2016. "Quantifying the impact of feedstock quality on the design of bioenergy supply chain networks.” Energies 9 (3): 203.

CEFIC. 2015. Competitiveness of the European Chemical Industry: How to Regain Ground in the Global Market. Brussels: European Chemical Industry Council.

CEFIC. 2016. Cefic Views on the Circular Economy. Position Paper December 2015 - Annex: February 2016. Brussels: European Chemical Industry Council.

Chen, J. C., Cheng, C.-H., and P. B., Huang. 2013. "Supply chain management with lean production and RFID application: A case study." Expert Systems with Applications 40 (9): 3389-3397.

Chen, P.-S., and M.-T. Wu. 2013. "A modified failure mode and effects analysis method for supplier selection problems in the supply chain risk environment: A case study." Computers \& Industrial Engineering 66 (4): 634-642. 
Cheng, M. C. B., and J. J. Wang. 2016. “An integrative approach in measuring hub-port supply chain performance: Potential contributions of a logistics and transport data exchange platform." Case Studies on Transport Policy 4 (2): 150-160.

Choi, T. Y., and Y. Hong. 2002. "Unveiling the structure of supply networks: Case studies in Honda, Acura, and DaimlerChrysler." Journal of Operations Management 20 (5): 469493.

Čuček, L., Klemeš, J. J., Varbanov, P. S., and Z. Kravanja. 2015. "Significance of environmental footprints for evaluating sustainability and security of development." Clean Technologies and Environmental Policy 17: 2125-2141.

Dadhich, P., Genovese, A., Kumar, N., and A. Acquaye. 2015. "Developing sustainable supply chains in the UK construction industry: A case study." International Journal of Production Economics 164: 271-284.

Dansereau, L. P., El-Halwagi, M., Chambost, V., and P. Stuart. 2014. "Methodology for biorefinery portfolio assessment using supply-chain fundamentals of bioproducts." Biofuels, Bioproducts and Biorefining 8: 716-727.

Despeisse, M., Mbaye, F., Ball, P. D., and A. Levers. 2012. "The emergence of sustainable manufacturing practices.” Production Planning \& Control 23 (5): 354-376.

DOE. 2016. Bioenergy Technologies Office: Multi-year Program Plan. Washington, DC: U.S. Department of Energy.

Ekşioğlu, S. D., Acharya, A., Leightley, L. E., and S. Arora. 2009. "Analyzing the design and management of biomass-to-biorefinery supply chain." Computers \& Industrial Engineering 57 (4): 1342-1352.

EPSRC. 2012. "EPSRC Sustainable Chemical Feedstocks - Call type: Expression of Interest." Engineering and Physical Sciences Research Council, February 07. Accessed 19 March 
2016. https://www.epsrc.ac.uk/files/funding/calls/2012/sustainable-chemical-

\section{feedstocks-call-document/}

Fahimnia, B., Sarkis, J., Dehghanian, F., Banihashemi, N., and S. Rahman. 2013. "The impact of carbon pricing on a closed-loop supply chain: an Australian case study." Journal of Cleaner Production 59: 210-225.

Fisher, M. L. 1997. "What is the right supply chain for your product?" Harvard Business Review 75 (2): 105-116.

Gebreslassie, B. H., Yao, Y., and F. You. 2012. "Multiobjective optimization of hydrocarbon biorefinery supply chain designs under uncertainty." American Institute of Chemical Engineers Journal 58 (7): 2155-2179.

Genovese, A., Acquaye, A. A., Figueroa, A., and S.C. L. Koh. 2015. "Sustainable supply chain management and the transition towards a circular economy: Evidence and some applications.” Omega 66 (Part B): 344-357.

Genovese, A., Koh, S.C. L., Kumar, N., and P. K. Tripathi. 2014. "Exploring the challenges in implementing supplier environmental performance measurement models: a case study." Production Planning \& Control 25 (13-14): 1198-1211.

GIA. 2014. Biodegradable Polymers - A Global Strategic Business Report. San Jose, CA: Global Industry Analysis.

Gold, S., and S. Seuring. 2011. "Supply chain and logistics issues of bio-energy production." Journal of Cleaner Production 19 (1): 32-42.

Hall, J., Matos, S., and B. Silvestre. 2012. "Understanding why firms should invest in sustainable supply chains: A complexity approach.” International Journal of Production Research 50 (5): 1332-1348.

Hasani, A., and A. Khosrojerdi. 2016. "Robust global supply chain network design under disruption and uncertainty considering resilience strategies: A parallel memetic 
algorithm for a real-life case study." Transportation Research Part E: Logistics and Transportation Review 87: 20-52.

Hosseini, S. A., and N. Shah. 2011. "Multi-scale process and supply chain modelling: From lignocellulosic feedstock to process and products." Interface Focus 1 (2): 255-262.

Ilić, M., and M. Nikolić. 2016. "Drivers for development of circular economy - A case study of Serbia." Habitat International 56: 191-200.

Jayaram, J., Dixit, M., and J. Motwani. 2014. "Supply chain management capability of small and medium sized family businesses in India: A multiple case study approach." International Journal of Production Economics 147: 472-485.

Johnson, M., and C. Mena. 2008. "Supply chain management for servitised products: A multiindustry case study." International Journal of Production Economics 114 (1): 27-39.

Karttunen, K., and J. Laitila. 2015. "Forest management regime options for integrated smalldiameter wood harvesting and supply chain from young Scots pine (Pinus sylvestris L.) stands.” International Journal of Forest Engineering 26 (2): 124-138.

Kawaguchi, H., Hasunuma, T., Ogino, C., and A. Kondo. 2016. "Bioprocessing of bio-based chemicals produced from lignocellulosic feedstocks." Current Opinion in Biotechnology 42: $30-39$.

Kazemzadeh, N., and G. Hu. 2013. "Optimization models for biorefinery supply chain network design under uncertainty." Journal of Renewable and Sustainable Energy 5: 053125.

Keim, W. 2010. "Petrochemicals: Raw material change from fossil to biomass?" Petroleum Chemistry 50 (4): 298-304.

Khan, O., Christopher, M., and B. Burnes. 2008. "The impact of product design on supply chain risk: A case study." International Journal of Physical Distribution \& Logistics Management 38 (5): 412-432. 
Kim, J., Realff, M. J., and J. H. Lee. 2010. "Simultaneous design and operation decisions for biorefinery supply chain networks: Centralized vs. distributed system.” In: Proceedings of the $9^{\text {th }}$ International Symposium on Dynamics and Control of Process Systems (DYCOPS 2010), Leuven, Belgium, July 5-7.

Kulak, M., Nemecek, T., Frossard, E., and G. Gaillard. 2016. "Eco-efficiency improvement by using integrative design and life cycle assessment. The case study of alternative bread supply chains in France.” Journal of Cleaner Production 112 (Part 4): 2452-2461.

Kumar, M., Srai, J. S., Pattinson, L., and M. Gregory. 2013. "Mapping of the UK food supply chains: Capturing trends and structural changes." Journal of Advances in Management Research 10: 299-326.

Kurian, J. K., Nair, G. R., Hussain, A., and G. S. Vijaya Raghavan. 2013. "Feedstocks, logistics and pre-treatment processes for sustainable lignocellulosic biorefineries: A comprehensive review." Renewable and Sustainable Energy Reviews 25: 205-219.

Lambert, D. M., and M. C. Cooper. 2000. "Issues in supply chain management." Industrial Marketing Management 29 (1): 65-83.

Lamers, P., Tan, E. C.D., Searcy, E. M., Scarlata, C. J., Cafferty, K. G., and J. J. Jacobson. 2015. "Strategic supply system design - a holistic evaluation of operational and production cost for a biorefinery supply chain." Biofuels, Bioproducts and Biorefining 9 (6): 648-660.

Lamming, R., Johnsen, T., Zheng, J., and C. Harland. 2000. “An initial classification of supply networks." International Journal of Operations \& Production Management 20 (6): 675691.

Levy, Y., and T. J. Ellis. 2006. “A systems approach to conduct an effective literature review in support of information systems research.” Informing Science Journal 9: 181-212. 
Li, W., Li, Q., Zheng, L., Wang, Y., Zhang, J., Yu, Z., and Y. Zhang. 2015. "Potential biodiesel and biogas production from corncob by anaerobic fermentation and black soldier fly." Bioresource Technology 194: 276-282.

Lieder, M., and A. Rashid. 2016. "Towards circular economy implementation: a comprehensive review in context of manufacturing industry." Journal of Cleaner Production 115: 36-51.

Lim, C. H., and H. L. Lam. 2015. "Functionality of element targeting approach in dynamic biomass resources supply chain system." Chemical Engineering Transactions 45: 18551860.

Lim, C. H., and H. L. Lam. 2016. "Biomass supply chain optimisation via novel Biomass Element Life Cycle Analysis (BELCA).” Applied Energy 161: 733-745.

Mansoornejad, B., Chambost, V., and P. R. Stuart. 2010. “Integrating product portfolio design and supply chain design for the forest biorefinery" Computers \& Chemical Engineering 34 (9): 1497-1506.

Mansoornejad, B., Pistikopoulos, E. N., and P. R. Stuart. 2011. "Incorporating flexibility design into supply chain design for forest biorefinery." Journal of Science \& Technology for Forest Products and Processes 1 (2): 54-66.

Mansoornejad, B., Pistikopoulos, E. N., and P. R. Stuart. 2013a. "Scenario-based strategic supply chain design and analysis for the forest biorefinery using an operational supply chain model." International Journal of Production Economics 144 (2): 618-634.

Mansoornejad, B., Pistikopoulos, E. N., and P. R. Stuart. 2013b. "Metrics for evaluating the forest biorefinery supply chain performance." Computers \& Chemical Engineering 54: $125-139$. 
Marvin, W. A., Schmidt, L. D., and P. Daoutidis. 2012. "Biorefinery location and technology selection through supply chain optimization." Industrial and Engineering Chemistry Research 52 (9): 3192-3208.

Matharu, A. S., de Melo, E. M., and J. A. Houghton. 2016. “Opportunity for high value-added chemicals from food supply chain wastes.” Bioresource Technology 215: 123-130.

Mayerle, S. F., and J. N. de Figueiredo. 2016. "Designing optimal supply chains for anaerobic bio-digestion/energy generation complexes with distributed small farm feedstock sourcing." Renewable Energy 90: 46-54.

McKinnon, A. 2004. Supply Chain Excellence in the European Chemical Industry. Technical Report. Brussels: CEFIC and The European Petrochemical Association.

Melero, J. A., Iglesias, J., and A. Garcia. 2012. "Biomass as renewable feedstock in standard refinery units. Feasibility, opportunities and challenges." Chemical Engineering Research and Design 5: 7393-7420.

Michelsen, O., Fet, A. M., and A. Dahlsrud. 2006. "Eco-efficiency in extended supply chains: A case study of furniture production." Journal of Environmental Management 79 (3): $290-297$.

Mirabella, N., Castellani, V., and S. Sala. 2014. "LCA for assessing environmental benefit of eco-design strategies and forest wood short supply chain: A furniture case study." The International Journal of Life Cycle Assessment 19 (8): 1536-1550.

Mobini, M., Sowlati, T., and S. Sokhansanj. 2013. "A simulation model for the design and analysis of wood pellet supply chains." Applied Energy 111: 1239-1249.

Mongeon, P., and A. Paul-Hus. 2016. "The journal coverage of Web of Science and Scopus: a comparative analysis." Scientometrics 106: 213-228. 
Nasir, M. H. A., Genovese, A., Acquaye, A. A., Koh S. C. L., and F. Yamoah. 2017. "Comparing linear and circular supply chains: A case study from the construction industry." International Journal of Production Economics 183 (Part B): 443-457.

Naso, D., Surico, M., Turchiano, B., and U. Kaymak. 2007. “Genetic algorithms for supplychain scheduling: A case study in the distribution of ready-mixed concrete." European Journal of Operational Research 177 (3): 2069-2099.

Newes, E. K., Bush, B. W., Peck, C. T., and S. O. Peterson. 2015. "Potential leverage points for development of the cellulosic ethanol industry supply chain.” Biofuels 6 (1-2): 2129.

Oke, A., and M. Gopalakrishnan. 2009. "Managing disruptions in supply chains: A case study of a retail supply chain.” International Journal of Production Economics 118 (1): 168174.

Ortiz-Gutiérrez, R. A., Giarola, S., and F. Bezzo. 2013. “Optimal design of ethanol supply chains considering carbon trading effects and multiple technologies for side-product exploitation.” Environmental Technology 34: 13-14.

Pagell, M., and Z. Wu. 2009. "Building a more complete theory of sustainable supply chain management using case studies of 10 exemplars.” Journal of Supply Chain Management 45 (2): $37-56$.

Paulo, H., Barbosa-Póvoa, A., and S. Relvas. 2013. "Modeling integrated biorefinery supply chains." Computer Aided Chemical Engineering 32: 79-84.

Reeb, C. W., Venditti, R., Hays, T., Daystar, J., Gonzalez, R., and S. Kelley. 2015. "Environmental LCA and financial analysis to evaluate the feasibility of bio-based sugar feedstock biomass supply globally: Part 1. Supply chain analysis.” BioResources 10 (4): 8098-8134. 
Ren, J., Manzardo, A., Toniolo, S., Scipioni, A., Tan, S., Dong, L., and S. Gao. 2013. "Design and modeling of sustainable bioethanol supply chain by minimizing the total ecological footprint in life cycle perspective.” Bioresource Technology 146: 771-774.

Rentizelas, A. A., Tolis, A. J., and I. P. Tatsiopoulos. 2009. "Logistics issues of biomass: The storage problem and the multi-biomass supply chain." Renewable and Sustainable Energy Reviews 13: 887-894.

Santibañez-Aguilar, J. E., Morales-Rodriguez, R., González-Campos, J. B., and J. M. PonceOrtega. 2016. "Stochastic design of biorefinery supply chains considering economic and environmental objectives.” Journal of Cleaner Production 136 (Part B): 224-245.

Serrano, A., Faulin, J., Astiz, P., Sánchez, M., and J. Belloso. 2015. "Locating and designing a biorefinery supply chain under uncertainty in Navarre: A stochastic facility location problem case." Transportation Research Procedia 10: 704-713.

Sharma, B., Ingalls, R. G., Jones, C. L., and A. Khanchi. 2013b. "Biomass supply chain design and analysis: Basis, overview, modeling, challenges, and future." Renewable and Sustainable Energy Reviews 24: 608-627.

Sharma, B., Ingalls, R. G., Jones, C. L., Huhnke, R. L., and A. Khanchi. 2013a. "Scenario optimization modeling approach for design and management of biomass-to-biorefinery supply chain system.” Bioresource Technology 150: 163-171.

Singh, A., Chu, Y., and F. You. 2014. "Biorefinery supply chain network design under competitive feedstock markets: An agent-based simulation and optimization approach." Industrial \& Engineering Chemistry Research 53 (39): 15111-15126.

Sosa, A., Acuna, M., McDonnell, K., and G. Devlin. 2015. "Controlling moisture content and truck configurations to model and optimise biomass supply chain logistics in Ireland.” Applied Energy 137: 338-351. 
Sporleder, T. L., Goldsmith, P. D., Cordier, J., and P. Godin. 2011. "Supply chains for emerging renewable polymers: Analysis of interactive sectors and complementary assets." International Food and Agribusiness Management Review 1 (2): 35-50.

Srai, J. S. 2010. A preliminary map of the UK Industrial Biotechnology Supply Chain. Cambridge: Institute for Manufacturing, University of Cambridge.

Srai, J. S. 2017. "Mapping industrial systems - a supply network perspective on enabling technologies, processes and actors." International Journal of Manufacturing Technology and Management 31: 82-99.

Srai, J. S., and M. Gregory. 2008. “A supply network configuration perspective on international supply chain development." International Journal of Operations \& Production Management 28 (5): 386-411.

Srai, J. S., Harrington, T. S., and M. K. Tiwari. 2016. "Characteristics of redistributed manufacturing systems: a comparative study of emerging industry supply networks." International Journal of Production Research 54 (23): 6936-6955.

Sukumara, S., Faulkner, W., Amundson, J., Badurdeen, F., and J. Seay. 2014. "A multidisciplinary decision support tool for evaluating multiple biorefinery conversion technologies and supply chain performance." Clean Technologies and Environmental Policy 16: 1027-1044.

Thimmappa, R., Geisler, K., Louveau, T., O’Maille, P., and A. Osbourn. 2014. "Triterpene biosynthesis in plants." Annual Review of Plant Biology 65: 225-257.

Tsolakis, N., Kumar, M., and J. S. Srai. 2016. Exploring opportunities for circular supply chains arising from renewable chemical feedstocks. In: Keynote papers presented at the 58 $8^{\text {th }}$ Annual Conference on Operational Research Society (OR58: The OR Society Annual Conference), Portsmouth University, Portsmouth, United Kingdom, September 6-8. 
Tsolakis, N., Keramydas, C., Toka, A., Aidonis, D., and E. Iakovou. 2014. “Agrifood supply chain management: A comprehensive hierarchical decision-making framework and a critical taxonomy." Biosystems Engineering, 120: 47-64.

Tsolakis, N., and J. S. Srai. 2016. Modelling 'green' paracetamol supply chain operations defined by renewable chemical feedstocks in England: A System Dynamics analysis. In: Proceedings of the $20^{\text {th }}$ International Manufacturing Symposium: Architecting the digital supply chain - the implications of digitalisation for global manufacturing, Institute for Manufacturing, University of Cambridge, Cambridge, United Kingdom, September 2930.

Tuck, C. O., Pérez, E., Horváth, I. T., Sheldon R. A., and M. Poliakoff. 2012. "Valorization of biomass: deriving more value from waste.” Science 337: 695-699.

Tuncel, G., and G. Alpan. 2010. "Risk assessment and management for supply chain networks: A case study." Computers in Industry 61 (3): 250-259.

UNEP. 2013. Global Chemicals Outlook: Towards Sound Management of Chemicals. Tysons Corner, Virginia: GPS Publishing.

UNGA. 2015. Resolution A/RES/70/1 - Transforming Our World: The 2030 Agenda for Sustainable Development. New York, NY: United Nations General Assembly.

USDA. 2015. Procurement Advisory No. 82A, USDA BioPreferred Program - Designated Biobased Items for Contract Requirements. Washington, DC: United States Department of Agriculture, Office of Procurement and Property Management.

Valente, C., Hillring, B. G., and B. Solberg. 2012. "Greenhouse gas emissions, energy use, and costs - Case studies of wood fuel supply chains in Scandinavia." International Journal of Forest Engineering 23 (2): 71-81. 
Walker, H. L., Seuring, S., Sarkis, J., and R. Klassen. 2014. "Sustainable operations management: recent trends and future directions." International Journal of Operations \& Production Management 34 (5).

Wu, W., and R. W. Davis. 2016. "One-pot bioconversion of algae biomass into terpenes for advanced biofuels and bioproducts." Algal Research 17: 316-320.

Xu, J., Jiang, J., Hse, C., and T. F. Shupe. 2012. "Renewable chemical feedstocks from integrated liquefaction processing of lignocellulosic materials using microwave energy." Green Chemistry 14 (10): 2821-2830.

Yeh, K., Realff, M. J., Lee, J. H., and C. Whittaker. 2014. “Analysis and comparison of single period single level and bilevel programming representations of a pre-existing timberlands supply chain with a new biorefinery facility." Computers \& Chemical Engineering 68: $242-254$.

Yeh, K., Whittaker, C., Realff, M. J., and J. H. Lee. 2015. "Two stage stochastic bilevel programming model of a pre-established timberlands supply chain with biorefinery investment interests." Computers \& Chemical Engineering 73: 141-153.

Yue, D., Kim, M. A., and F. You. 2013. "Design of sustainable product systems and supply chains with life cycle optimization based on functional unit: General modeling framework, mixed-integer nonlinear programming algorithms and case study on hydrocarbon biofuels.” ACS Sustainable Chemistry \& Engineering 1 (8): 1003-1014.

Zhai, M., Zhang, X., Cheng, F., Zhou, X., and X. Su. 2016. “A game-theoretic analysis of the government's role on the biomass supply chain construction." International Journal of Ambient Energy 0 (0): 1-15.

Zhang, F., Johnson, D. M., and M. A. Johnson. 2012. "Development of a simulation model of biomass supply chain for biofuel production.” Renewable Energy 44: 380-391. 
Zhang, H.-Y., Ji, Q., and Y. Fan. 2013. “An evaluation framework for oil import security based on the supply chain with a case study focused on China." Energy Economics 38: 87-95.

Zhang, J., Osmani, A., Awudu, I., and V. Gonela. 2013. “An integrated optimization model for switchgrass-based bioethanol supply chain.”Applied Energy 102: 1205-1217.

Zhang, L., and G. Hu. 2013. "Supply chain design and operational planning models for biomass to drop-in fuel production." Biomass and Bioenergy 58: 238-250.

Zhang, Y., and M. M. Wright. 2014. "Product selection and supply chain optimization for fast pyrolysis and biorefinery system." Industrial and Engineering Chemistry Research 53: 19987-19999.

Zhang, Y., Goldberg, M., Tan, E. and P. A. Meyer. 2016. "Estimation of economic impacts of cellulosic biofuel production: a comparative analysis of three biofuel pathways." Biofuels, Bioproducts and Biorefining 10: 281-298. 
The Version of Record of this manuscript has been published and is available in Production Planning \& Control, published online 21 May 2018 , http://www.tandfonline.com/10.1080/09537287.2018.1449263

\section{Appendix}

Table A1. Salient points from the individual interviews with experts.

\begin{tabular}{|c|c|c|c|}
\hline & Expertise Area & Subject Matter Expertise & Interview Salient Points \\
\hline 1. & Chemistry & $\begin{array}{l}\text { Chemical routes to process } \\
\text { terpenes, as part of an ESPRC } \\
\text { funded project }\end{array}$ & $\begin{array}{l}\text { - Currently, chemists' work is focused on developing targeted chemical routes for processing } \\
\text { renewable chemical feedstocks (focus is on terpenes) to value added products. }\end{array}$ \\
\hline 2. & Chemistry & $\begin{array}{l}\text { Organic chemistry synthesis } \\
\text { routes }\end{array}$ & $\begin{array}{l}\text { - Approximately } 2 \% \text { of oil is used in the production of fine chemicals and } 6 \% \text { in the production of } \\
\text { polymers. There are about } 8 \text { dominant polymer types. } \\
\text { - Some of these polymers (e.g., monomers to produce PET) could at least partially be produced from } \\
\text { renewable chemical feedstocks, such as terpenes. However, the processes required still need to be } \\
\text { further developed and improved to be viable. } \\
\text { A key question in the field of renewable chemical feedstocks is the premium that people are willing } \\
\text { to pay for the derived "green" products, specifically pharmaceuticals. }\end{array}$ \\
\hline 3. & Chemistry & $\begin{array}{l}\text { Inorganic chemistry synthesis } \\
\text { routes, as part of an ESPRC } \\
\text { funded project }\end{array}$ & $\begin{array}{l}\text { - The polymer market seems to be a key opportunity to replace the use of petrochemical feedstocks } \\
\text { at a relatively large scale. } \\
\text { - The polymers that are developed from renewable chemical feedstocks, like for example terpenes, } \\
\text { are likely to be different from those currently produced from petrochemicals. They would therefore }\end{array}$ \\
\hline
\end{tabular}




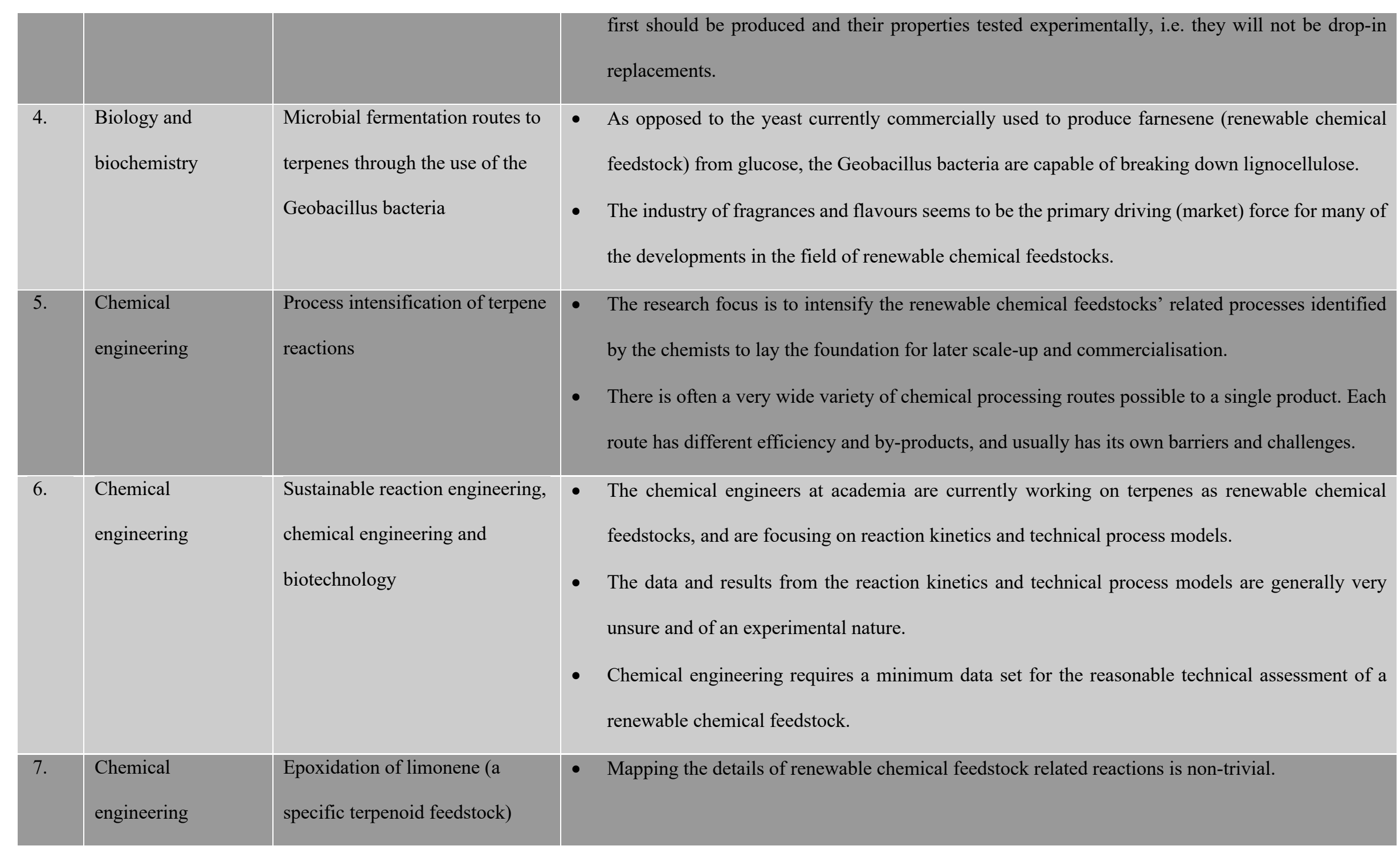




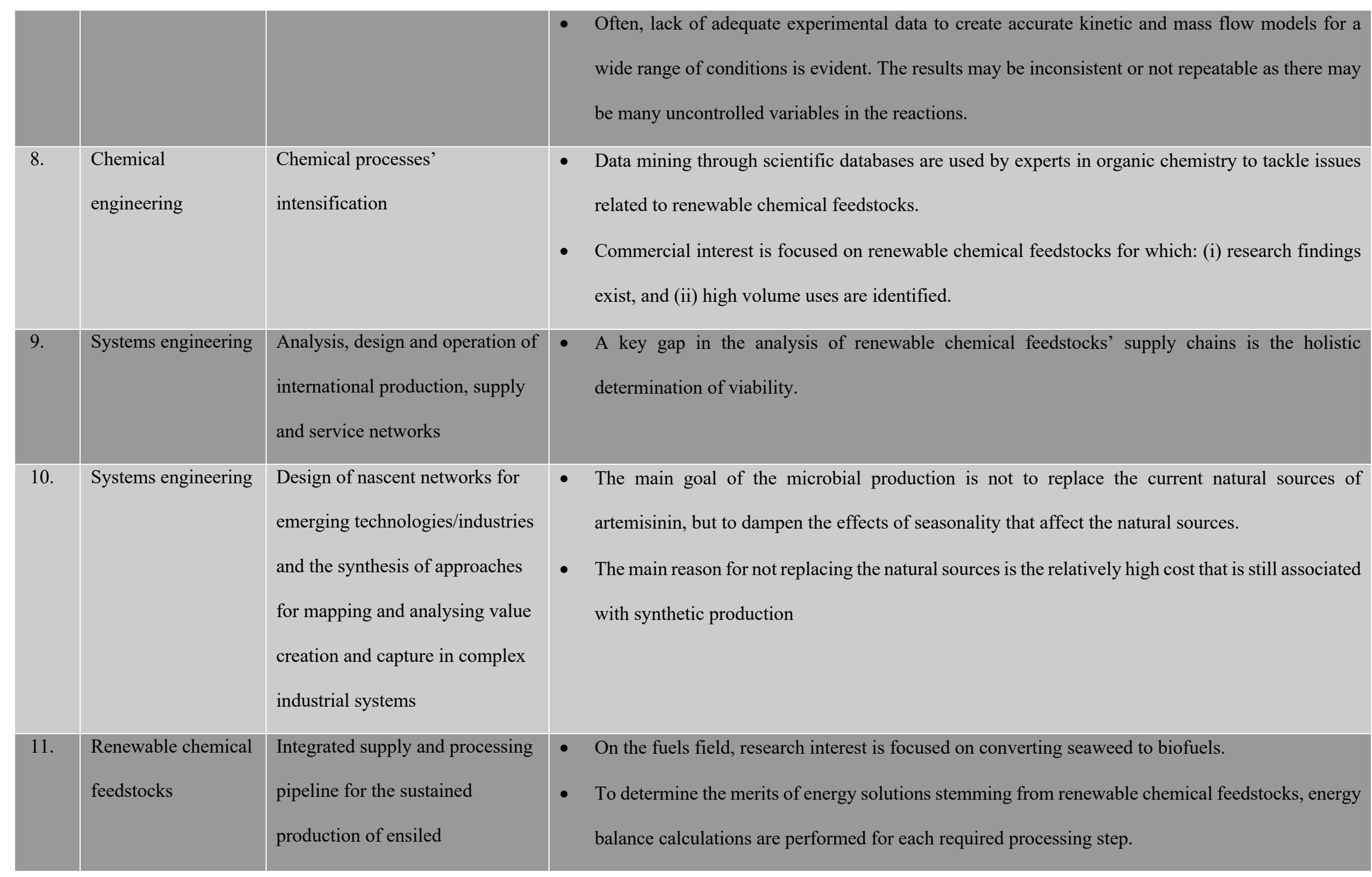




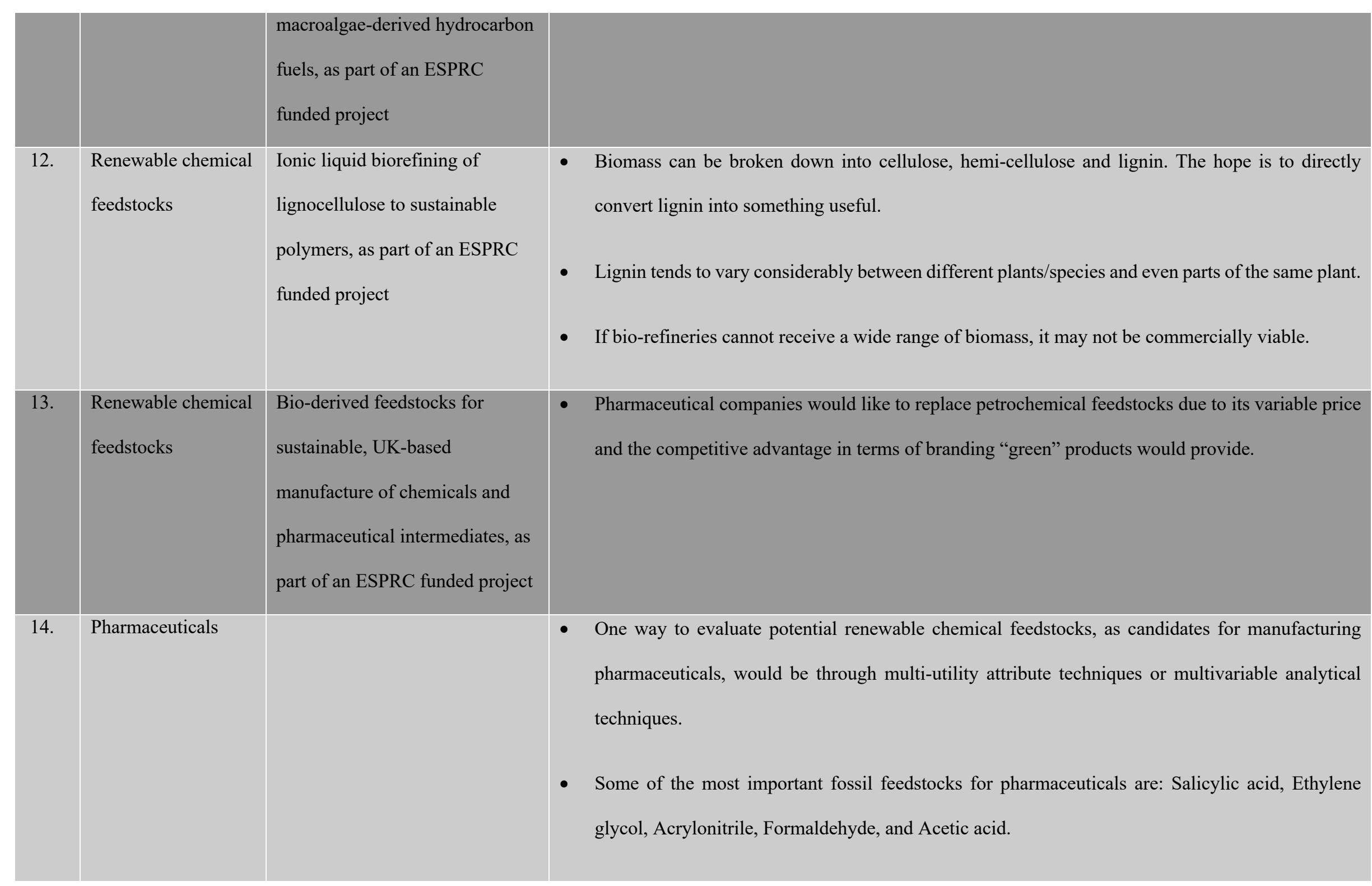

